\title{
4 Do green areas affect crime and safety?
}

\author{
Vania Ceccato, Ana Canabarro \\ and Lisandra Vazquez
}

\subsection{Introduction}

People's satisfaction with and perceptions of the quality of green areas are thought to be important in the creation of sustainable cities (Chiesura, 2004; Iqbal \& Ceccato, 2015; Mulliner \& Maliene, 2011). A green area (or space)be it a park, a forest, a meadow, a green belt-is often associated with environmental amenities in cities, place attachment, citizens' health and sustainability (Babey, Tan, Wolstein, \& Diamant, 2015; Bogar \& Beyer, 2015; Cohen et al., 2016; Gómez, Baur, Hill, \& Georgiev, 2015; Troy \& Grove, 2008). However, green areas are far from homogeneous in nature, function and other inherent qualities. Safety is one of the basic qualities that make a green area attractive and is an important component of sustainable environments (UN-Habitat, 2019; UNHSP, 2007). If a green area is unsafe, or at least felt so by its users, its quality most likely is compromised.

In this chapter we investigate the nature of green areas in relation to safety. This study builds on previous literature overviews (Bogar \& Beyer, 2015; Kondo, Fluehr, McKeon, \& Branas, 2018a) that assessed the state of evidence on relationships among green space, violence and crime. Bogar and Beyer (2015) focused on studies from the United States from 2001 and 2013. Overall, they found significant evidence to support the positive impacts of green space on safety, despite incompatible research designs and conflicting results. Kondo, Fluehr et al. (2018) found consistent negative associations between green space exposure and violence and health outcomes. They called for additional research and standardization among studies for a better understanding of the relationship between green areas and safety. This study responds to those calls by extending the review to literature from other parts of the world and looking into the relationship between green space and safety perceptions/fear of crime, which have been lacking.

The aim of this chapter is to identify and assess the nature of published, peerreviewed literature in English on the relationship between green areas (parks, forests, neighborhood parks, green vacant land, interstitial spaces) and crime and perceived safety. This is achieved by performing a systematic literature overview from 1968 to 2018 from the major databases and assessing thematic 
trends. We used the software VOSviewer (www.vosviewer.com) to manage and organize the vast material spanning five decades into two overarching themes: the relationship between green areas and crime, and the relationship between green areas and fear or poor perceived safety. This literature review aims to collect and systematize scholarly knowledge on the topic to respond to the following questions.

1. Which are the most common types of green areas associated with crime and/or poor perceived safety in the international literature?

2. Do green areas affect the occurrence of crime and disorder and, if so, how?

3. Do green areas impact on perceived safety and, if so, what are the mechanisms?

This chapter is structured as follows. First, we discuss the basic definitions and theoretical necessary principles, then report the methods, followed by the results. In the final section we identify gaps in the literature and suggest a research agenda on green areas and safety as well as policy implications of the current knowledge.

Note that in this study "green areas" and "green spaces" will be used interchangeably.

\subsection{Theory and definitions of green areas and safety}

\section{Types of green areas and crime}

Goode and Collins (2014) categorized green spaces in six groups according to their origin, development and walkability. Although the categories were created for green areas in the British context, they can be helpful to illustrate the spectrum of green areas found in other parts of the world. The first category is "tended" green spaces for pleasure and is composed of squares, parks and campuses, botanical gardens, gardens, tree-lined streets, flowerbeds, verges and pockets of space. The second category is called "tended" green spaces for use, and is composed of allotments, playing fields, greens and playgrounds, graveyards and cemeteries. Then, they suggest "un-tended" green spaces, such as disused railway lines and wasteland, and water features, such as those green areas close by rivers, streams, lakes and ponds, canals, conduits and millstreams, dockyards and waterfronts. In addition, there are "natural" green spaces, for example, meadows, heaths and woodland, and finally "controlled" green spaces, which include green belts and nature reserves.

Green areas (or spaces) tend to be associated with amenities and safety but not everywhere (Ceccato \& Hanson, 2013; Groff \& McCord, 2011; Iqbal \& Ceccato, 2015). Vacant lands and/or interstitial spaces with greenery may be considered an indication not of environmental quality but quite the opposite, as they may attract problems, such as littering, and more serious crimes, such as drugs, robbery and rape, that seriously affect urban quality (Iqbal \& Ceccato, 2015; Troyer \& Wright, 1985). 
The international literature on green spaces and safety covers a wide spectrum of environments, from parks to interstitial spaces, of varied sizes and functions. What are the most common types of green areas linked to issues of crime and poor perceived safety? Size, location and function are important determinants of safety in a green area (Iqbal \& Ceccato, 2016), as are temporal factors that interact with the city structure and people's routine activity (Cohen \& Felson, 1979). Brantingham and Brantingham (1984) suggested that offenders become familiar with the places that are relevant to them ("nodes") and the corridors that link them ("paths"). These nodes and paths constitute offenders' awareness space, and it is within or on the fringes of this space that they are most likely to commit an offense. Green areas can be nodes or areas in those paths located within many offenders' awareness space and can become a risky place.

\section{Green areas as risky places}

A green area can become a risky place, namely a place that concentrates a disproportionately high number of crimes in relation to its surroundings (Clarke \& Eck, 2007). As a risky place, a green area can be a crime generator (Brantingham \& Brantingham, 1995); in other words, people with criminal motivation can be drawn to, for example, a desolated park that provides the basic conditions for crime to happen. Crime generators are risky places with many criminal opportunities that are well known to offenders, such as an open drug market in a park. A park can also be a crime attractor; for example, a green area attracts large numbers of people for reasons unrelated to criminal motivation, creating many opportunities for crime (Groff \& McCord, 2011; Hilborn, 2009; Iqbal \& Ceccato, 2015). A green area can also become a crime enabler when there is little regulation of behavior at that place: rules of conduct are absent or not enforced (Clarke \& Eck, 2005). The physical and social environment, the maintenance of the place (e.g., illumination) and the mechanisms that reinforce guardianship (e.g., "eyes on the park") are fundamental to keeping it safe. Green areas can also become crime radiators or crime absorbers (Bowers, 2014). Bowers (2014, p. 389) explored the nature of the relationship between a particular place and what occurs outside but near the place. Crime radiators "cause crime in the immediate environment as well as internally", while crime absorbers absorb risk from the external locale.

Whether a green area is a risky place depends on the context, not only spatially (by type of land use, inner city-outskirts, rural-urban) but also temporally (by hour of the day, day of the week, seasonally). The type of green area, its function and design influence what occurs in it as well as in places surrounding it. This implies that environments can be planned, built and modified following design principles that reduce the opportunities for crime. This can be done by stimulating surveillance at particular times, fostering territoriality and reducing areas of conflict by controlling access and improving overall perceived safety (Armitage, 2013; Cozens, Saville, \& Hillier, 2005; Ekblom, 2011, 
2019; Iqbal \& Ceccato, 2016; Jeffery, 1971, 1977; Newman, 1972; Saville, 2019).

\section{Green areas and safety perceptions}

A desolate, unsafe park can reduce the walkability of the whole area where it is located. The mechanisms linking individuals and safety vary, but they are often associated with the inherent qualities of environments (streets and places) that encourage individuals to use them. People in the streets create "eyes on the streets" (Jacobs, 1961), which can affect the risk of crime and safety perceptions (Cohen \& Felson, 1979; Reynald, 2010). Indeed, Talen and Koschinsky (2014) indicated that the quality of the urban environment, social interaction, safety and health are interrelated. Fear of crime can change and limit an individual's activities (Giurgescu et al., 2017; Jackson \& Gouseti, 2012; Lorenc et al., 2013), restricting her/his own mobility and ultimately her/his health.

Yet, the way we perceive the environment is also a function of what we are. Individual factors play a role in defining perceptions of risk and safety. Previous research confirms that an individual's fears depend on individual physical abilities as well as on age, gender, sexual status, ethnicity and socioeconomic background (Box, Hale, \& Andrews, 1988; Garofalo \& Laub, 1979; Pain \& Smith, 2008). Therefore, the nature of perceived safety (or the lack thereof, i.e., fear) is a multi-faceted and multi-scale phenomenon (Day, 2009; Los, 2002; Wyant, 2008), a result of the intersection of an individual's characteristics and the environments to which he/she is exposed.

\subsection{Methodology}

The literature search covered 50 years, from 1968 to 2018, of publications in the following databases: Scopus and Google Scholar. Although our search extended back 50 years, articles in this particular topic only started to appear in journals in the 1980s and 1990s. The bibliographic selection was conducted in two steps: first, we focused on the bibliometric analysis and then on in-depth analysis of the material.

Three combinations of keywords were used to search in each database, as shown in Table 4.1. The searches were conducted in July 2019 and aimed to combine terms related to crime, fear or different kinds of violence with the ones linked to green areas. This is a review of literature inspired by the principles of the Cochrane Handbook for Systematic Reviews (Higgins \& Green, 2011) as well as the PRISMA checklist (Moher, Liberati, Tetzlaff, \& Altman, 2009 ). One of the features that distinguish this type of review from others is the pre-specification of studies following a set of eligibility criteria (Higgins \& Green, 2011). The flowchart in Figure 4.1 illustrates an approximate estimation of the articles during the process of collection and selection of the publications. 
Table 4.1 Sets of keywords, number of results and documents selected from Google Scholar and Scopus

\begin{tabular}{|c|c|c|c|}
\hline Database & Keywords & Results & Selected \\
\hline \multirow[t]{3}{*}{ Scopus } & $\begin{array}{l}\text { ((crim* OR fear* OR safe*) AND } \\
\text { (vegetation* OR green* OR park* OR } \\
\text { "tended spaces" OR “vacant lots" OR } \\
\text { natur* OR forest* OR tree OR trees OR } \\
\text { planta* OR grass*) AND (hedonic* OR } \\
\text { pay OR value OR pric*)) }\end{array}$ & 16 & 4 \\
\hline & 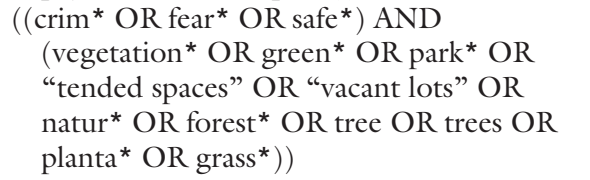 & 1,045 & 68 \\
\hline & $\begin{array}{l}\text { ((burglar* OR larcen* OR theft* OR } \\
\text { murder* OR assault* OR robber* OR } \\
\text { felon* OR aggressi* OR violenc* OR } \\
\text { disorder OR offence) AND (vegetation* } \\
\text { OR green* OR park* OR "tended spaces" } \\
\text { OR "vacant lots" OR forest* OR tree OR } \\
\text { trees OR planta* OR grass*)) }\end{array}$ & 640 & 23 \\
\hline \multirow[t]{3}{*}{$\begin{array}{l}\text { Google } \\
\text { Scholar }\end{array}$} & $\begin{array}{l}\text { (crime OR fear OR safe OR safety) + } \\
\text { (“tended spaces” OR “vacant lots” OR } \\
\text { nature OR forest OR tree OR trees OR } \\
\text { plantation OR grass OR green OR parks } \\
\text { OR park OR vegetation) + (prices OR } \\
\text { price OR value OR values OR pay OR } \\
\text { hedonic) }\end{array}$ & 20 & 3 \\
\hline & $\begin{array}{l}\text { (crime OR fear OR safe OR safety) + } \\
\text { ("tended spaces" OR "vacant lots" OR } \\
\text { nature OR forest OR tree OR trees OR } \\
\text { plantation OR grass OR green OR parks } \\
\text { OR park OR vegetation) }\end{array}$ & 2,940 & 6 \\
\hline & $\begin{array}{l}\text { (burglary OR larceny OR theft OR murder } \\
\text { OR assault OR robbery OR felony OR } \\
\text { aggression OR violence OR offence) + } \\
\text { (“tended spaces" OR “vacant lots" OR } \\
\text { forest OR tree OR trees OR plantation } \\
\text { OR grass OR green OR vegetation } \\
\text { OR park) }\end{array}$ & 328 & 4 \\
\hline Total & & 4,989 & 108 \\
\hline
\end{tabular}

\section{Bibliometric analysis}

The bibliometric analysis included only 95 articles obtained and selected from Scopus (in * ${ }^{*}$.ris) in the data collection process. VOSviewer version 1.6.12 (www.vosviewer.com) is a free-access software tool that was used to create bibliometric maps based on the keywords cited in each selected article and to group terms in clusters according to their linkages. The map in VOSviewer was 


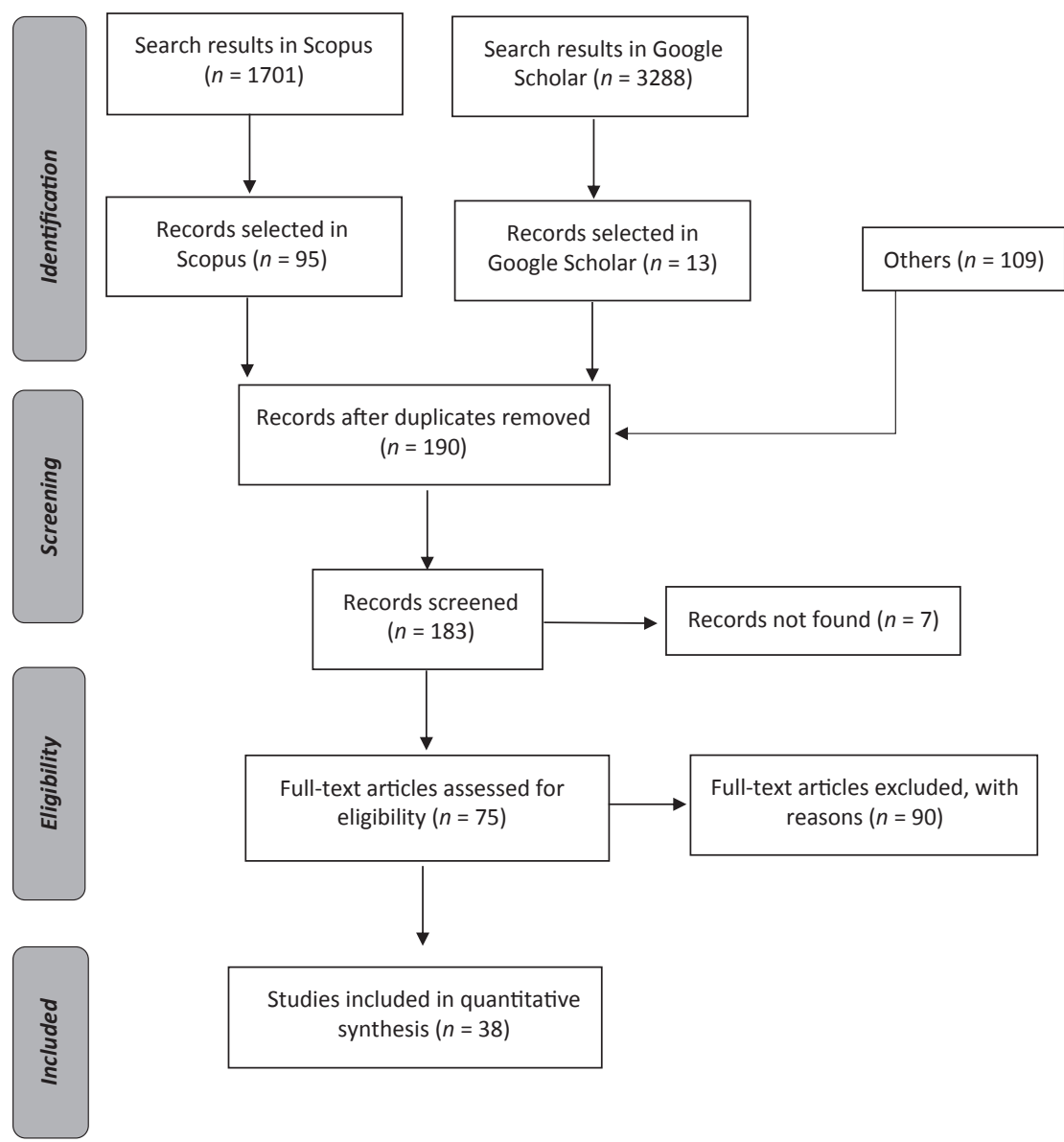

Figure 4.1 Data collection and selection in Scopus and Google Scholar, 1968-2018.

created based on the bibliometric data, and the 95 articles mentioned above were used as input data. The co-occurrence analysis was performed using the keywords adopting the counting method. It resulted in a total of 800 terms, of which only 244 met the threshold of the minimum number of two occurrences/repetitions. This criterion of a minimum of two repetitions was selected to avoid terms without links or with weak links to the theme and at the same time to ensure the coverage of the terms and representativeness of the articles. The final selection resulted in 95 items out of the 244 keywords, and the map was created using the default settings. We performed thematic content analysis. Output files from the database were used to produce informative network maps by theme. A number of themes were selected based on the clusters that emerged from the literature and are discussed in Section 4.4. 


\section{In-depth analysis}

In addition to the search on Scopus, we also searched Google Scholar. In some cases, one of the keywords was excluded from one of the searches to make the results more specific to the target subject. Our inclusion and exclusion criteria for both databases are presented in Table 4.2. The total was 4,989 publications, of which 66 percent were from Google Scholar (Table 4.1). Unfortunately, the results were too general, so only the first 10 pages were considered for evaluation. The advantage of using Google Scholar is that this platform includes papers published before 1970, which were lacking in the Scopus search. Only 38 were eligible (articles that contained links between green areas, crime and/ or fear) and constitute the base for the analysis (Tables A4.1-A4.3 in the Appendix). In a few cases, articles appear in two different tables because they evaluate both crime and fear. These themes support the selection of topics that are relevant to be investigated in detail and that are discussed in the literature overview, more specifically the correlation or effect of green areas on crime and/or safety:

- Positive: decline of crime and increase of safety perceptions, an expected effect

- Negative: green areas have unexpected effect on crime and/or safety/fear

- Inconclusive: different effects were observed in different variables

- No difference: no statistically significant impact or crime and/or fear of crime remained the same (before and after interventions, for example)

Table 4.2 Inclusion and exclusion criteria

\begin{tabular}{|c|c|c|c|}
\hline Criteria & Inclusion & Exclusion & Database \\
\hline 1. Year & 1968-2018 & Others & $\begin{array}{l}\text { Scopus and } \\
\text { Google Scholar }\end{array}$ \\
\hline 2. Language & English & Others & $\begin{array}{l}\text { Scopus and } \\
\text { Google Scholar }\end{array}$ \\
\hline 3. Document & $\begin{array}{l}\text { Article, Book, Chapter, } \\
\text { Review }\end{array}$ & Others & Scopus \\
\hline 4. Subject Area & $\begin{array}{l}\text { Engineering; Medicine; } \\
\text { Social Sciences; } \\
\text { Environmental Science; } \\
\text { Psychology; Economics, } \\
\text { Econometrics and } \\
\text { Finance; Multidisciplinary; } \\
\text { Undefined }\end{array}$ & Others & Scopus \\
\hline 5. Field & Title & Others & Google Scholar \\
\hline 6. & Null & $\begin{array}{l}\text { Include } \\
\text { Patents, } \\
\text { Include } \\
\text { citations }\end{array}$ & Google Scholar \\
\hline 7. & Sort by relevance & Null & Google Scholar \\
\hline
\end{tabular}




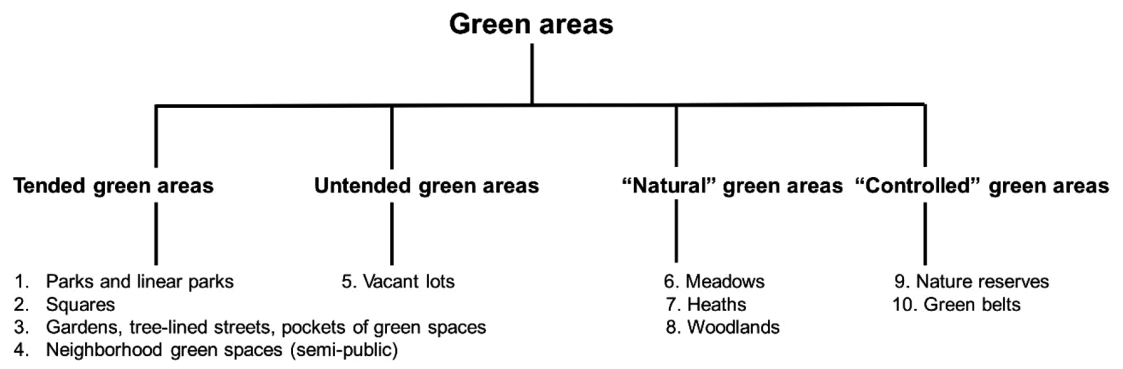

Figure 4.2 The categorization of green areas adapted from Goode and Collins (2014).

The cities in the studies are classified into the following five types: (1) global cities and/or capitals; (2) regional capitals; (3) local city centers; (4) small towns and/or communities; and (5) other. Green areas were also classified into the categories suggested by Goode and Collins (2014) and are numbered as suggested in Figure 4.2.

\subsection{Results and discussion}

This study builds on two current systematic literatures (Bogar \& Beyer, 2015; Kondo et al., 2018a) that assessed the evidence on relationships among green space, violence and crime. These authors call for additional research and standardization among research studies to better understand the relationship between urban green space, violence and crime. Below we discuss the results, also including publications that deal with green areas and fear, in articles from around the world written in English.

\section{Green areas and safety: overall patterns}

The bibliometric analysis resulted in seven themes as an outcome of the literature search (Figure 4.3(a)). The themes vary from crime and safety, to design of the urban environment and neighborhood, residence characteristics and urban health, taken from Scopus and Google Scholar, 1968-2018. The greater the weight of an item, the larger the circle. Most of the articles link greenspace/ areas, crime and safety, urban area, perception and neighborhood issues. The distance between two keywords indicates the relatedness of the keywords, in terms of co-citation links. Figure 4.3(b) corresponds to the density visualization of authors' keywords based on total occurrences, association strength. The analysis of the overall pattern has been complemented with an in-depth analysis of 38 articles, which is discussed below.

The vast majority of the studies focused on "type 1 green areas," namely those categorized as "tended green spaces for pleasure," as suggested by Goode and 

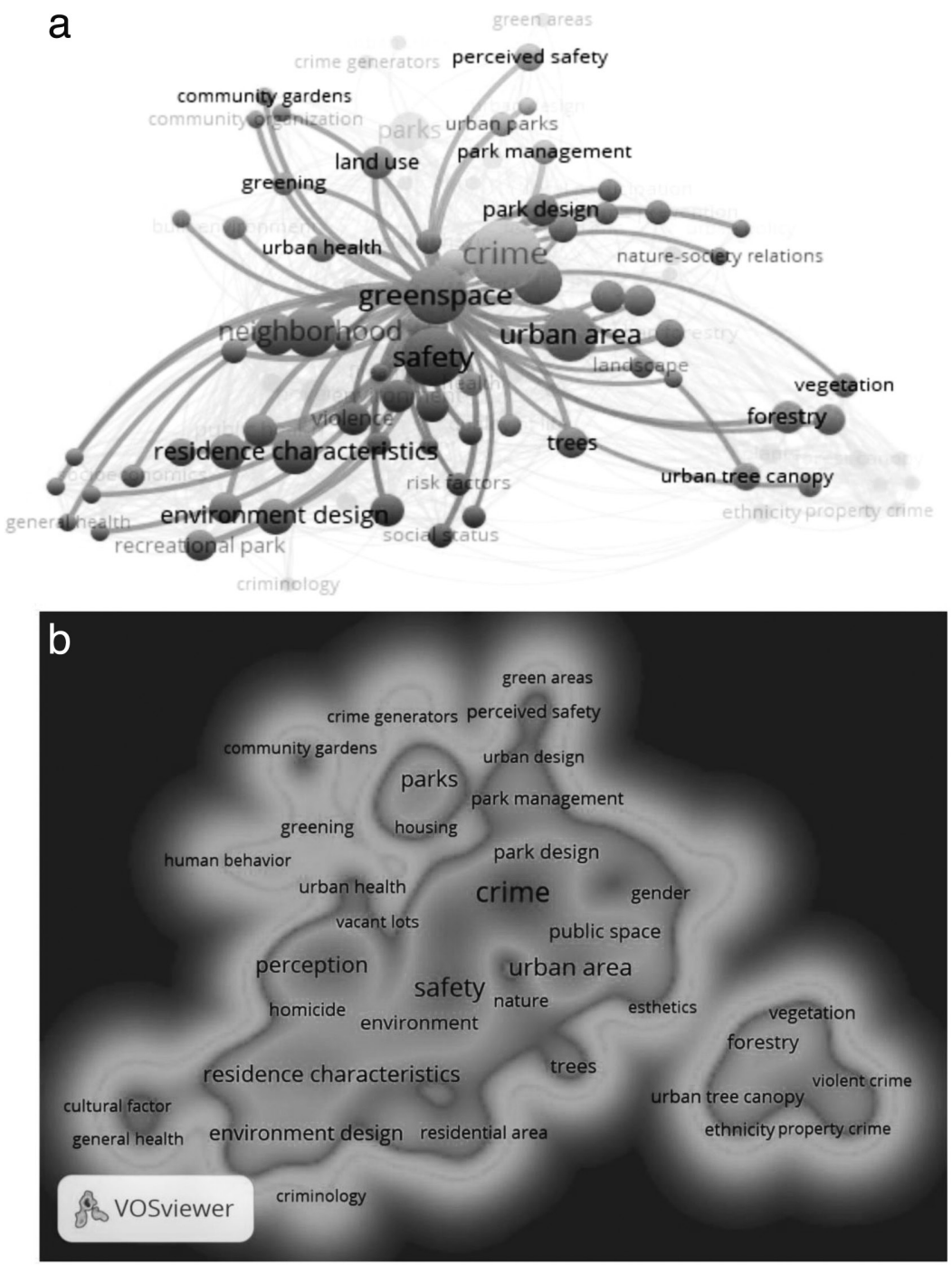

Figure 4.3 Literature search for keyword: "greenspace" in publications that relate to crime and fear of crime, 1968-2018. (a) Network visualization map with focus on "greenspace" as an example in Scopus, 1968-2018. (b) Density visualization of author keywords, 1968-2018, in Scopus based on total occurrences, association strength.

Collins (2014), including squares, parks and campuses (Figure 4.2). This finding is based on the in-depth analysis collected from 38 articles. Around 70 percent of these studies are from North America, 15 percent from European countries, and 15 percent from Asia, Australia and other countries. In North America, the sites 


\section{Vania Ceccato et al.}

might vary between global/capital cities and regional capitals (Cleveland, Denver, Philadelphia, New Haven, Cincinnati, Portland). Only two were in the local urban centers of Youngstown, Ohio, and Flint, Michigan (Appendix).

Out of 38 articles, 43 percent deal with the relationship between crime and green spaces and 47 percent green spaces and safety perception/fear, while 10 percent dealt with both crime and fear in relation to a variety of types of green area (Figure 4.4(a)). As much as 41 percent of the articles show that green areas affect safety positively (for example: vegetation in abundance is associated with lower rates of assault, robbery and burglary; in low-income neighborhoods residents perceived nearby parks as being safe; and interventions in a park decreased

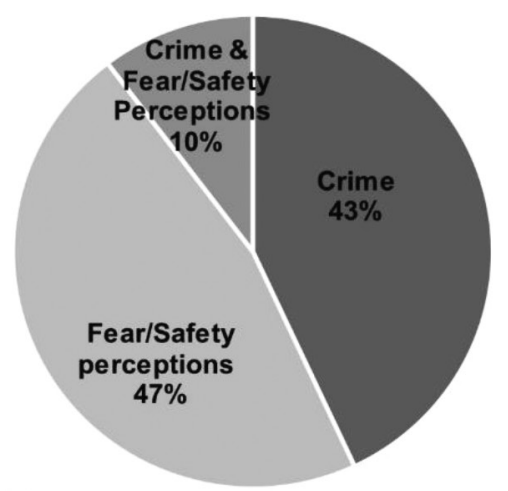

(a) Studies by safety measure

$N=38(16+18+4=38)$

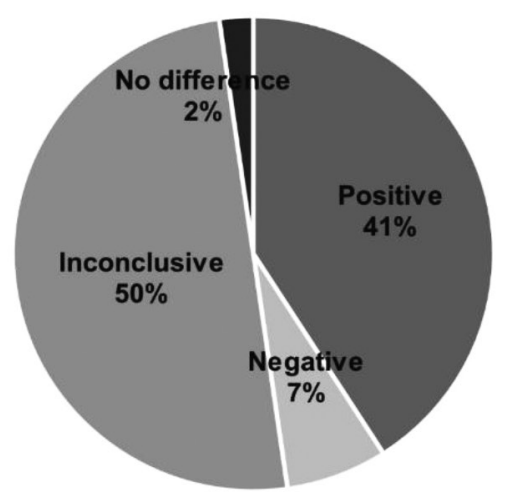

(b) Studies by relationship with green areas

Figure 4.4 Analysis of the relationship of green areas and crime and fear/perceived safety. 
overall crime compared with those areas that did not receive an intervention), while 7 percent of the articles indicate that green areas have a negative impact (for example, increased crime), 50 percent of the articles show inconclusive/ conflicting results (different effects were observed in different variables) and 2 percent showed no effect, or not statistically significant (Figure 4.4(b)).

\section{Green areas and crime}

Although the studies show conflicting results, the overall pattern is that green areas do not seem to be related to an increase in crime. On the contrary, there were certain studies that revealed that green areas had a decreasing effect on crime, or that safety interventions decreased crime in green areas and/or neighborhoods. Eight articles suggested that green areas are not associated with crime occurrence or increase (Gilstad-Hayden et al., 2015; Heinze et al., 2018; Kondo, Andreyeva et al., 2018; Kondo, Fluehr et al., 2018; Kondo, Han et al., 2017; Kondo, South et al., 2017; Kuo \& Sullivan, 2001a; Wolfe \& Mennis, 2012; Ye et al., 2018), and two did not show any evidence either way (Garvin et al., 2013; Kimpton et al., 2017). Among those studies that did not show the negative effect of green areas, two studies focused on vacant lots in urban areas, four investigated trees and vegetation coverage in cities, and two analyzed the neighborhood-scale green areas around big cities. Outcomes for crime were categorized by type of crime according to the articles as shown in Appendix, Table A4.1.

Nearly all studies are cross-sectional analyses. One exception was the study by Branas et al. (2018) that analyzed a total of 541 randomly sampled vacant lots that were assigned into treatment and control study arms; outcomes from police and 445 randomly sampled participants were analyzed over a 38-month study period. Participants living near "treated" vacant lots reported significantly reduced perceptions of crime, vandalism and safety concerns when going outside their homes as well as increased use of outside spaces for relaxing and socializing. Significant reductions in crime overall and nuisances were also found after the treatment of vacant lots in neighborhoods below the poverty line.

In our sample that covered studies on all continents, we found that regression models were used six times with varying research designs. Quasi-experimental, difference-in-difference analysis, autocorrelations, circular statistics and geocoded mappings were also applied. Mixed methods were also common. For example, Groff and McCord (2011) performed a field survey and combined it with statistical analysis (location quotients and comparison) to examine the relationship between parks and crime and disorder in Philadelphia.

Maintenance of green areas and parks plays an important role when it comes to the relationship between green areas and crime. Vacant lots that are well managed and maintained, for instance, have less crime (Branas et al., 2011; Heinze et al., 2018) and better perceived safety (Branas et al., 2011; Garvin et al., 2013; Heinze et al., 2018). Better maintained vacant lots have fewer assaults, gun assaults, vandalism and violent crimes than street segments with vacant, abandoned and untreated lots (Branas et al., 2011; Heinze et al., 2018). 
In addition, being under and around tree coverage is associated with violence, property crimes, gun assault and total crime (Branas et al., 2011; GilstadHayden et al., 2015; Kondo, Han, et al., 2017; Ye et al., 2018). This appears to support former findings from research conducted in big cities where trees and other vegetation were associated with total crime and disorder. In addition, the effect of good maintenance was noted in previous studies from the 1990s. Poyner (1994), for example, illustrated the effect of demolition in the UK, showing that robberies and snatches decreased. In the United States, Freedman and Owens (2011) showed that new construction and rehabilitation have led to significant reductions in violent crime that is measurable at the county level, although there are no detectable effects on property crime. Similarly, Aliprantis and Hartley (2015) estimated the effects of closures and demolition in Chicago; findings showed a significant decrease in homicides around demolitions. Note that these studies (Poyner, 1994, Freedman \& Owens, 2011; Aliprantis \& Hartley, 2015) were not included in our review because their primary focus was on demolitions, so they did not satisfy the selection criteria.

However, crime seems to have been associated with green areas in three studies. For example, the study of Kondo, Han et al. (2017) showed that tree damage caused by an invasive tree pest was associated with an increase in total crime (except damage/endangerment, burglary, robbery and rape). Further investigation revealed that certain types of green area are more crime-prone than others, meaning that when greenspaces are heterogeneous they can influence both the timing and the frequency of crime (Kimpton et al., 2017). Parks in an urban area, for instance, can be crime generators (Groff \& McCord, 2011).

\section{Green areas and safety perceptions}

Appendix Table A4.2 summarizes 18 articles that deal with fear of crime and perceived safety in green areas. Almost 41 percent of them showed positive effects on safety of the presence of green areas (Branas et al., 2011; Coley et al., 1997; Farbod et al., 2017; Garvin et al., 2013; Kuo et al., 1998; Lindgren \& Nilsen, 2012; Ward Thompson et al., 2013; Vaughan et al., 2018). These findings include the impact of green areas on health status (e.g., Branas et al., 2011). Among the types of green area reported in these articles, parks comprise 48 percent of studies, green areas in neighborhoods 30 percent and woodlands 13 percent. The remaining articles focused on the influence of woodlands and trees on perceived safety. In only six studies did fear of crime increase with green areas, but these findings mainly focused on specific groups and situations (Cohen et al., 2010; Loukaitou-Sideris \& Sideris, 2010; Madge, 1997; Parra et al., 2010; Shackleton et al., 2015; Stodolska \& Shinew, 2010). As many as 60 percent of articles were based in the United States, 23 percent Europe, 14 percent Asia and the remainder elsewhere.

Safety perceptions vary according to users' profiles in these green areas. Gender plays an important role in perceived safety in green areas, and women tend to report more fear of crime than men in these environments (Jorgensen et al., 2013; 
Kuo \& Sullivan, 2001b; Loukaitou-Sideris \& Sideris, 2010; Madge, 1997; Shackleton et al., 2015). The fear of crime in green areas is also influenced by other factors. Particular uses of the park may affect safety negatively, especially among women (Jorgensen et al., 2013). Interestingly, park use leads to more park use (performing sports competitions and recreational activities) but not safety alone (Cohen et al., 2010; Loukaitou-Sideris \& Sideris, 2010).

Four articles that relate fear of crime in green areas also link to the occurrence of crimes, such as vandalism and graffiti (Jansson et al., 2013; Maruthaveeran \& Van den Bosh, 2015; Parra et al., 2010; Stodolska \& Shinew, 2010). While Appendix, Table A4.3, demonstrates some overlap in outcome directions related to urban green areas, crime and fear (e.g., wellmaintained neighborhood parks demonstrate consistent decreases in crime and fear), the table also shows evidence of specific crimes and fear with opposite relationships with urban green space, or at least varying by type of crime, resident or time of day (e.g., perceived safety was dependent on the number of people present in the park). As these results tend to be inconclusive, we will not discuss them further.

\subsection{Final considerations}

This chapter set out to assess the nature of published peer-reviewed literature in English on the relationship between green areas and safety from 1968 to 2018. We first defined what we meant by green areas in the urban context, then we associated green areas with both actual risk of being victimized by crime and in relation to fear of crime and/or safety perceptions by users. The literature shows a predominately positive trend in the effect of green areas on safety (both crime and fear/safety perceptions), but about half of the studies show inconclusive or conflicting findings. Despite the fact that these findings are similar to what was suggested by previous literature overviews (Bogar \& Beyer, 2015; Kondo et al., 2018b), caution is necessary when drawing this conclusion.

First, the current body of literature is not extensive enough to determine the effects of all types of green area and all types of crime. As for the types of green area, our results were dominated by what Goode and Collins (2014) call "tended green spaces for pleasure", such as parks, botanical gardens and squares. In addition, the studies used different methods, which makes it difficult to compare conflicting findings. Various studies showed that the effect of green areas on safety was dependent on crime types, levels and contexts, but to what extent might these differences just be an artefact of the methods?

Second, although we report results and draw conclusions based on hundreds of publications, it is important to remember that publications in peer-reviewed journals are more likely to show positive "expected" results than results that are uncertain, negative or "unexpected". At the same time, it is impossible to estimate the "dark figure" of unpublished materials, in other words, to estimate how many studies had negative or unexpected results and were not published. 
Third, what works internationally in terms of the impact on green areas may not work locally. The literature reported in this overview is dominated by studies in North America and the UK. Caution should be exercised when conclusions drawn from findings that are country- or city-specific are applied to the context of cities in the Nordic countries, which have different city structures, climate, political and cultural contexts, and distinct urban planning traditions.

Despite these limitations, the contribution of this chapter is to extend the results to publications in English for other parts of the world beyond the United States. We went beyond the "park-crime link" and looked for evidence of potential relationships between green areas and perceived safety and fear of crime. Finally, despite the fact that most articles were quantitative pieces, we also considered studies that adopted mixed methods, allowing for examples of interventions on parks and consequently on safety.

\section{Research recommendations}

The results of this literature overview show opportunities for improving our understanding through future research. One of these future research areas is the need to better understand why certain types of green area become a crime magnet and others do not; namely, why they become risky places that generate (and/or attract, absorb or radiate) crime. The temporal and spatial contexts of green areas are important aspects to be considered. Another area that remains open for further research is the relationship between the use of spaces and the well-known mismatches between the design of crime-ridden micro-places and safety perceptions in multi-functional parks (Ceccato \& Hanson, 2013) (see also Chapter 5). Finally, one important area for future research is the testing of rigorous longitudinal methodologies that can provide assessments over time and be applied in contexts other than those that are tested here.

\section{Policy implications}

More than just risky places, green areas play an important role in the sustainability of cities, so it is essential to know about their safety qualities, as was the intention of this study. We have shown a predominately positive relationship between green areas and safety in the 38 studies. This impact must be contextualized both spatially and temporally to properly inform practices of maintenance of these public places.

Planning for a safe green area is part of creating a public place that is safe and inclusive for all. Park visitors, for instance, constitute only one group of users. There might be those who have the park as a working place (vendors), others who "just" pass by (transients and people waiting for a bus) or those who temporarily reside in them (homeless). Groff and McCord (2011) stated that parks and other green areas are contested spaces in cities. Since they are often publicly owned, they are at the same time everyone's and no one's. They may offer poor 
guardianship and therefore are susceptible to be taken over by illegal activities or activities that trigger fear among visitors.

Like many other public places, parks and squares accommodate groups that are often viewed as a security problem rather than as individuals who have a right to be there and feel safe. In these circumstances, getting the right person or organization to be responsible for these environments is important (knowing who is in charge of delivering security services for whom, where and when). In most cases in public places - and in particular parks - there are no quick fixes for safety problems. They demand a multi-pronged approach, with long-term engagement of multiple authors in collaborative frameworks. Inspired by theoretical principles of environmental criminology and situational crime prevention, fieldwork protocols (Ceccato, 2019) can be used to detect particular safety problems in parks and help practitioners to think systematically about solutions that can be effective, inclusive and sustainable. 


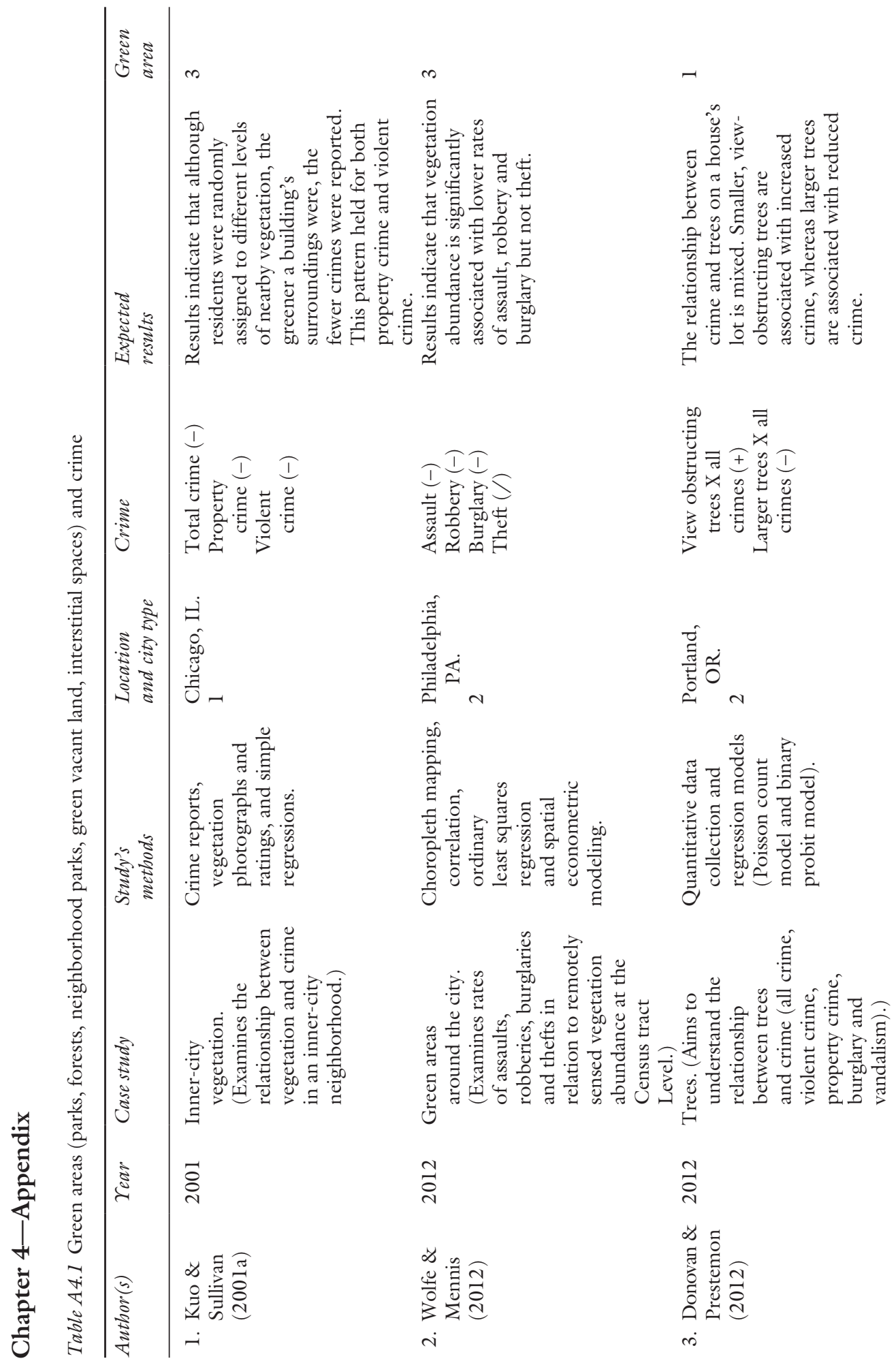




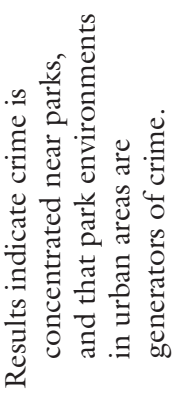

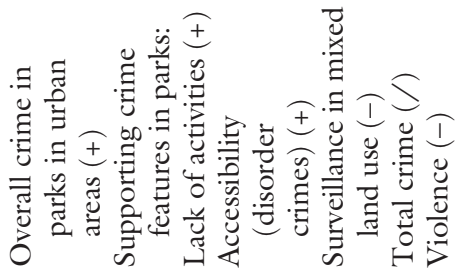
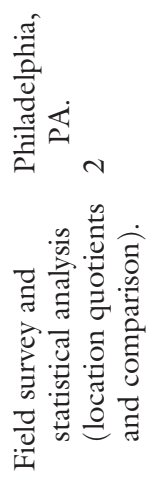

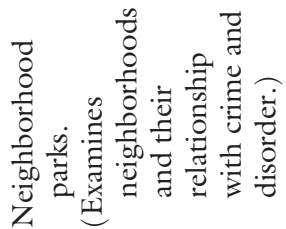

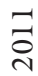

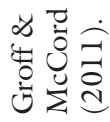

$+$

$\stackrel{10}{2}$
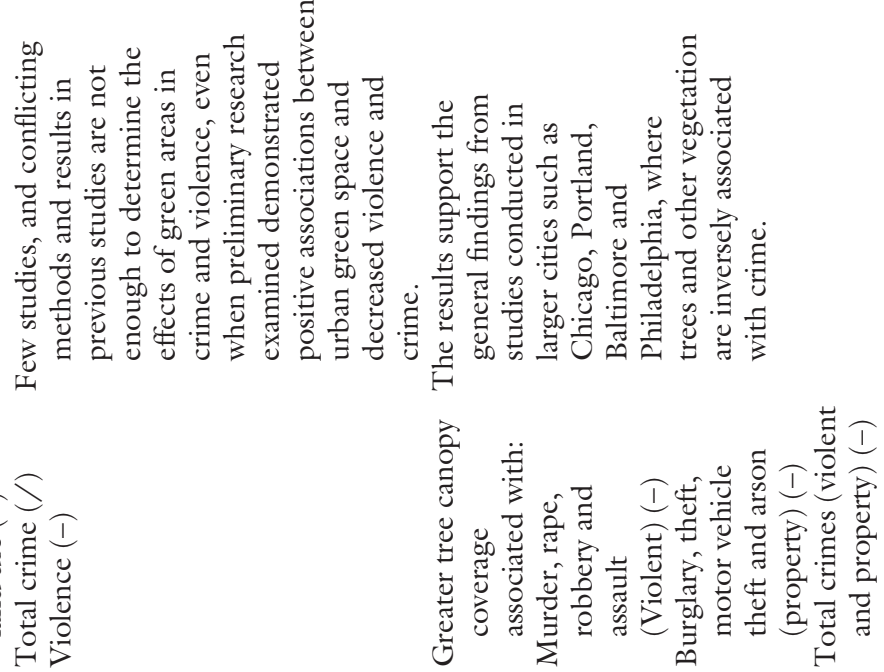

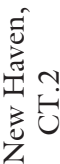
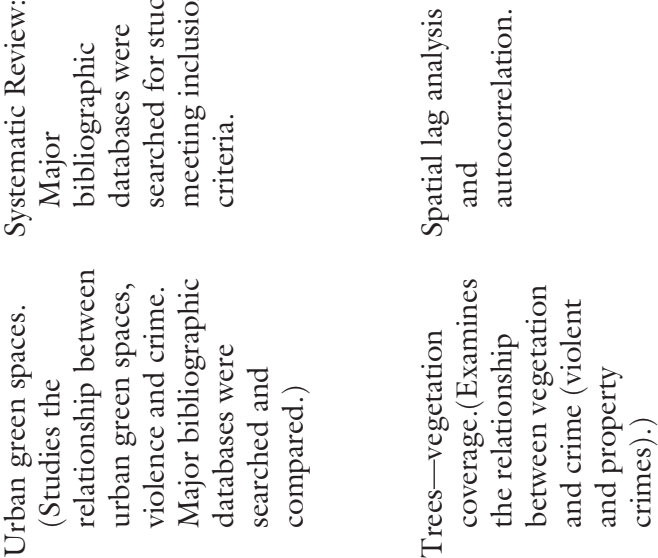

웅

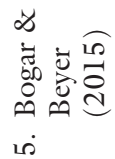




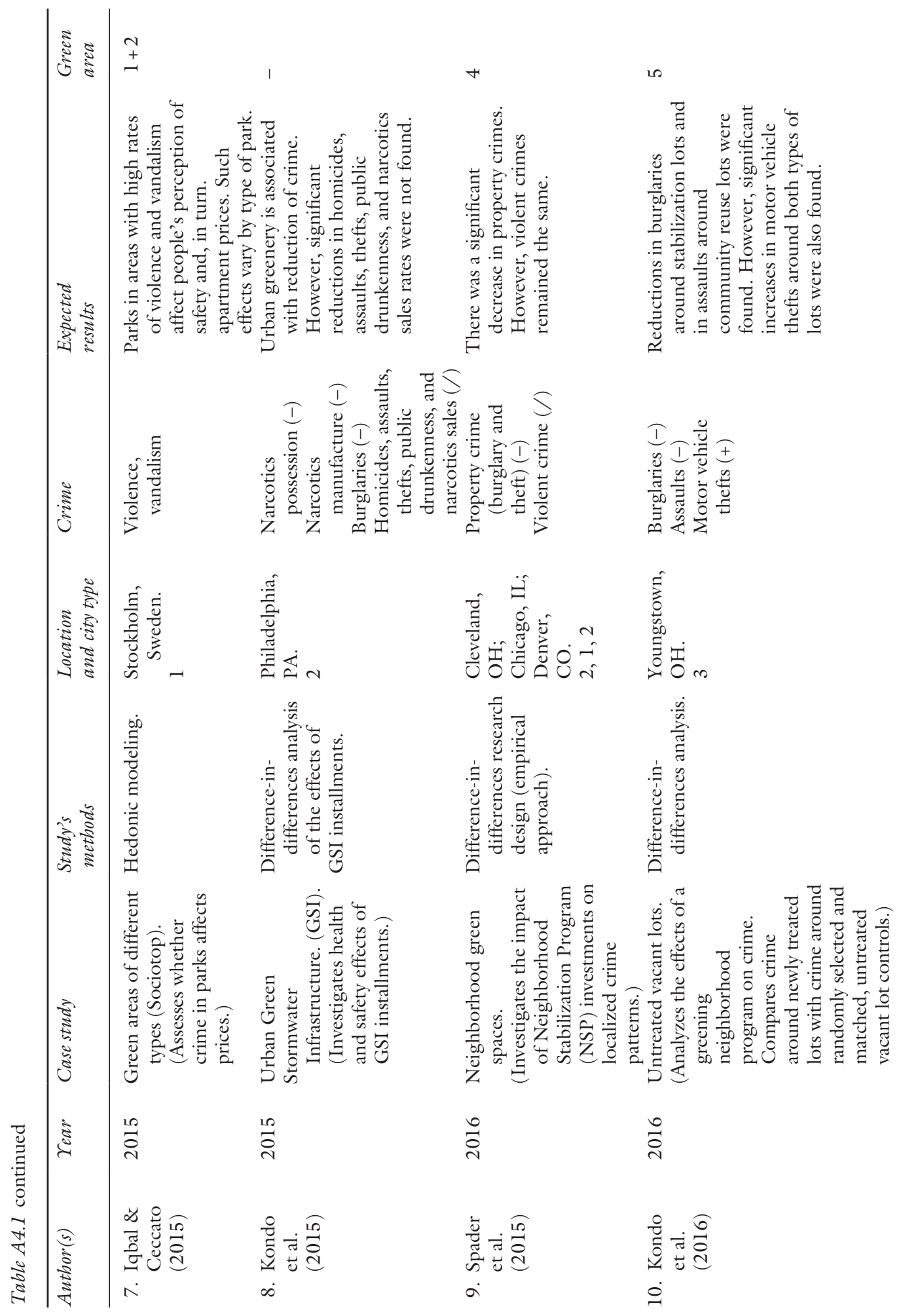



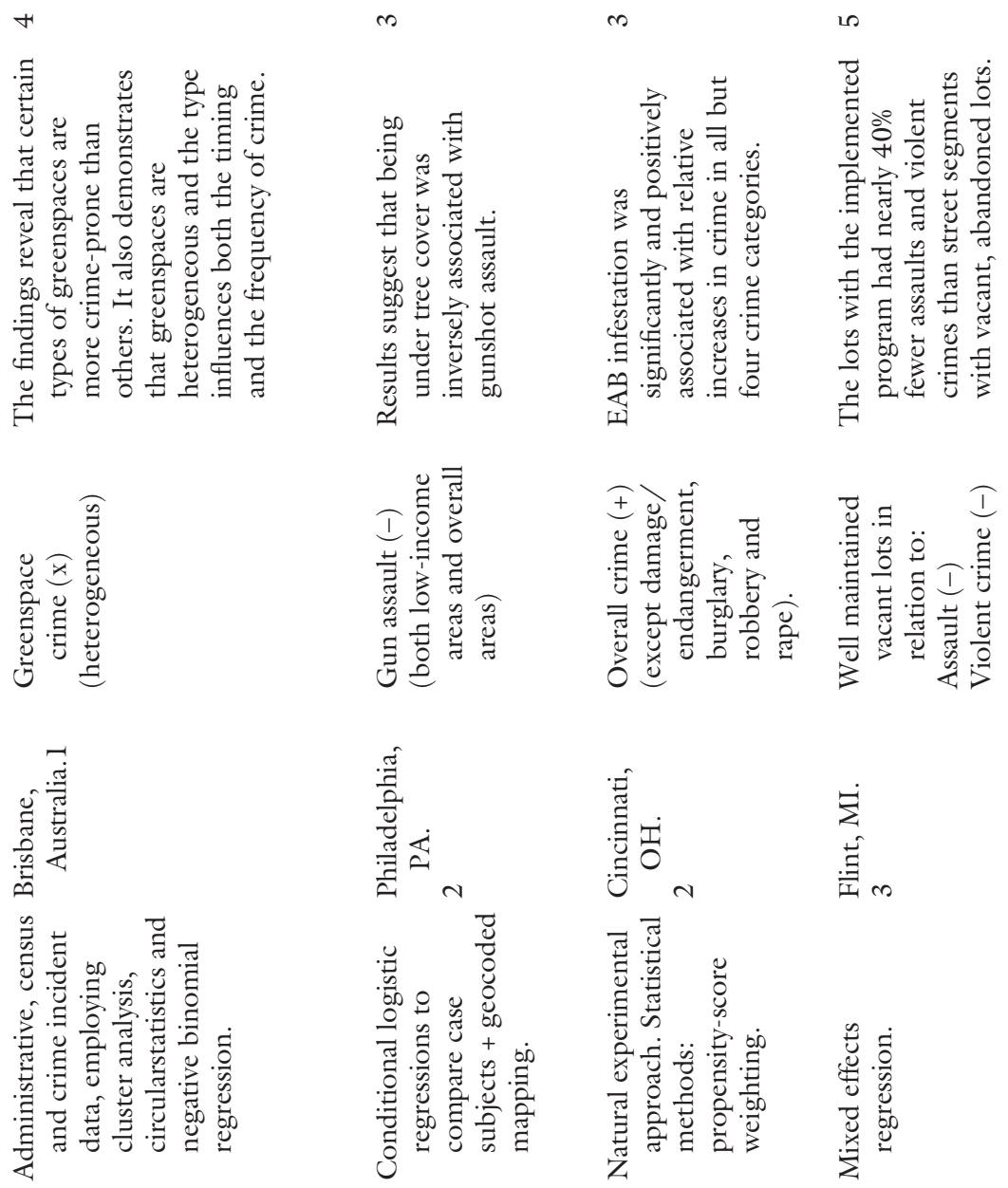

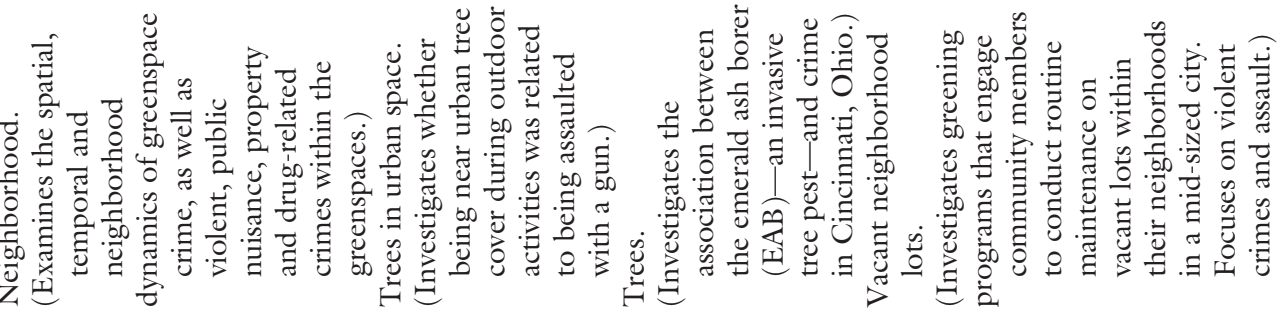

궁

공

ํㅗㅇ

임

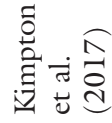

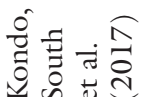

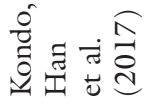

离

ㄱ.

$\ddot{2}$

ப 


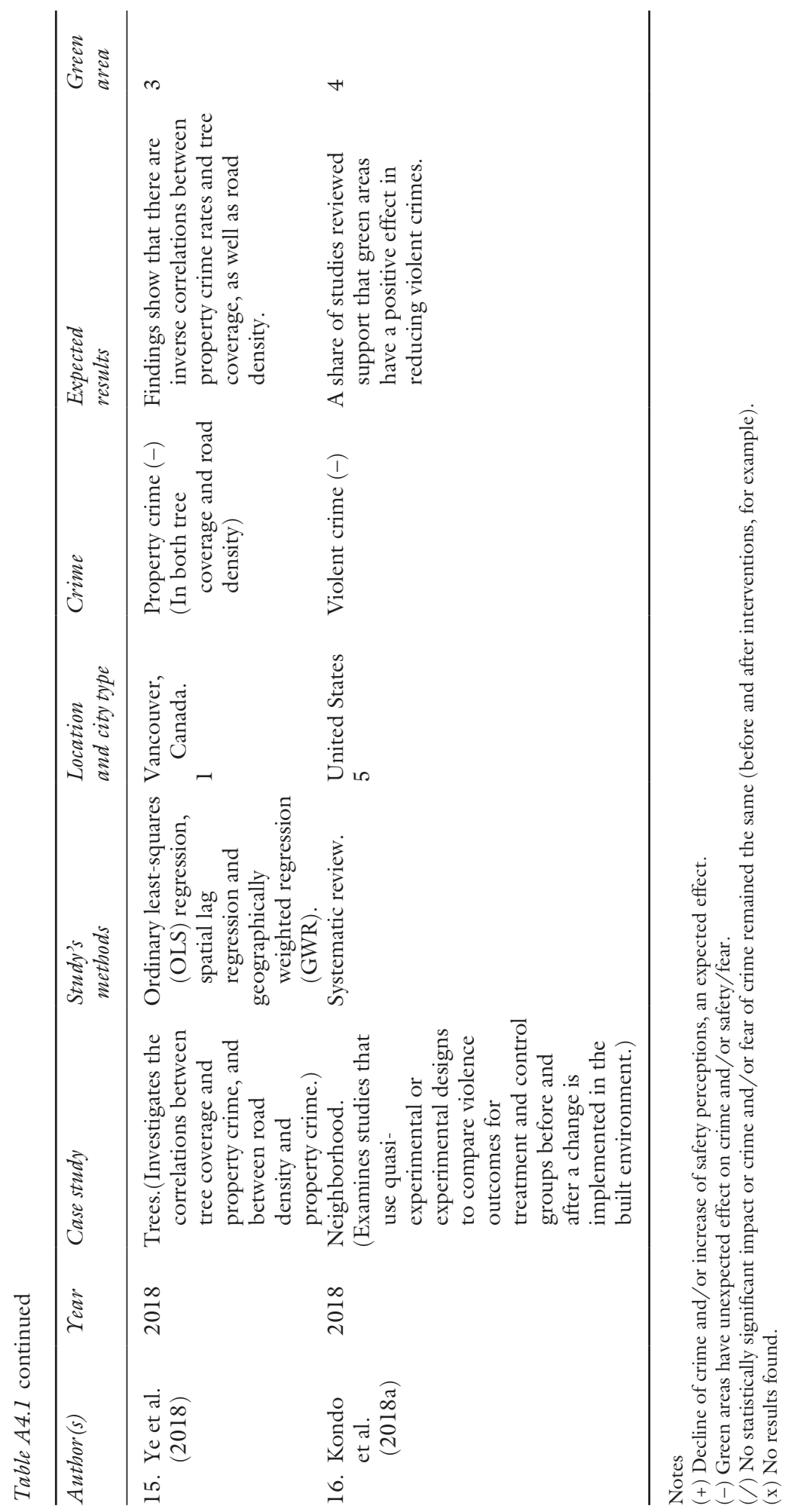


Do green areas affect crime and safety? 95

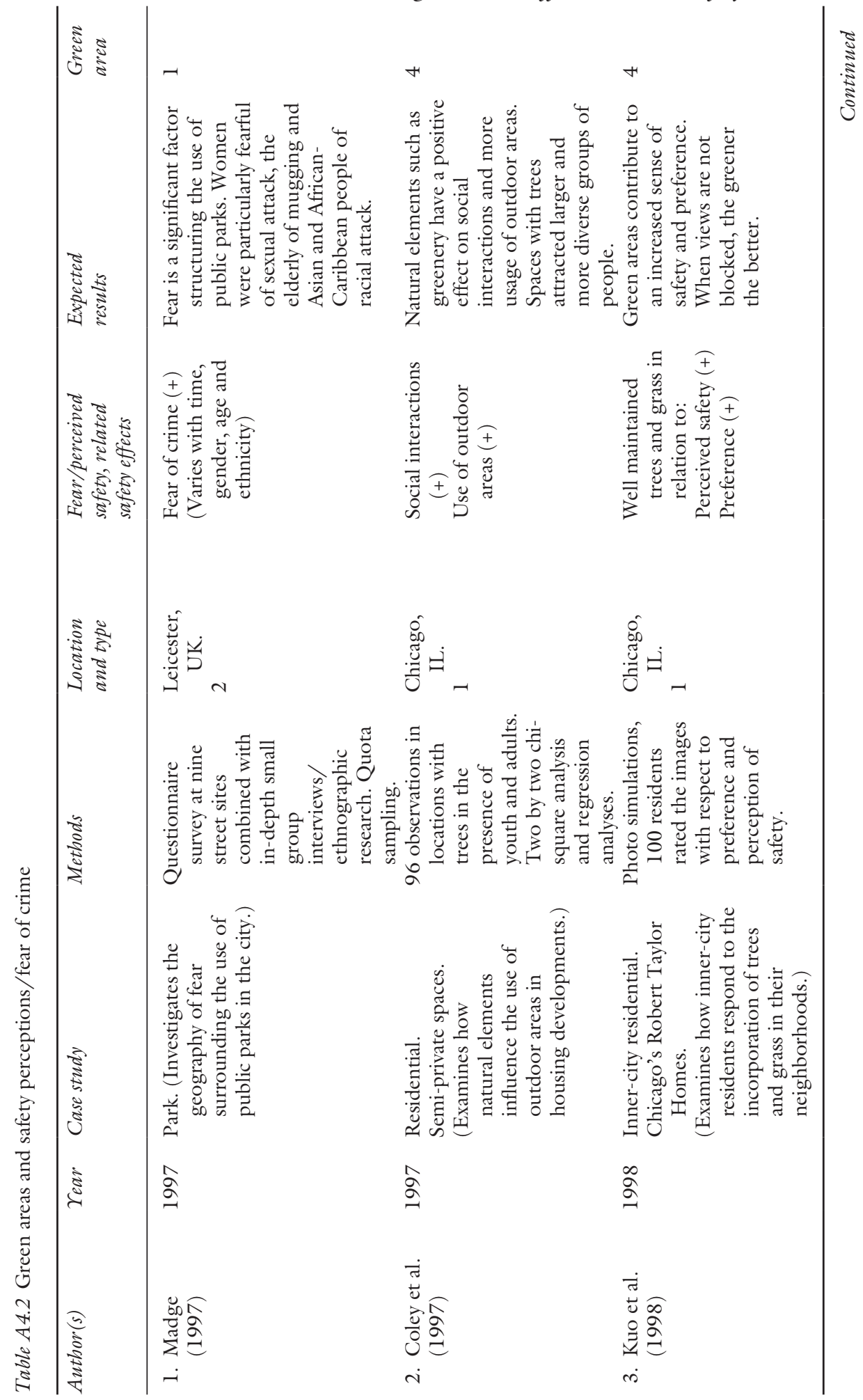




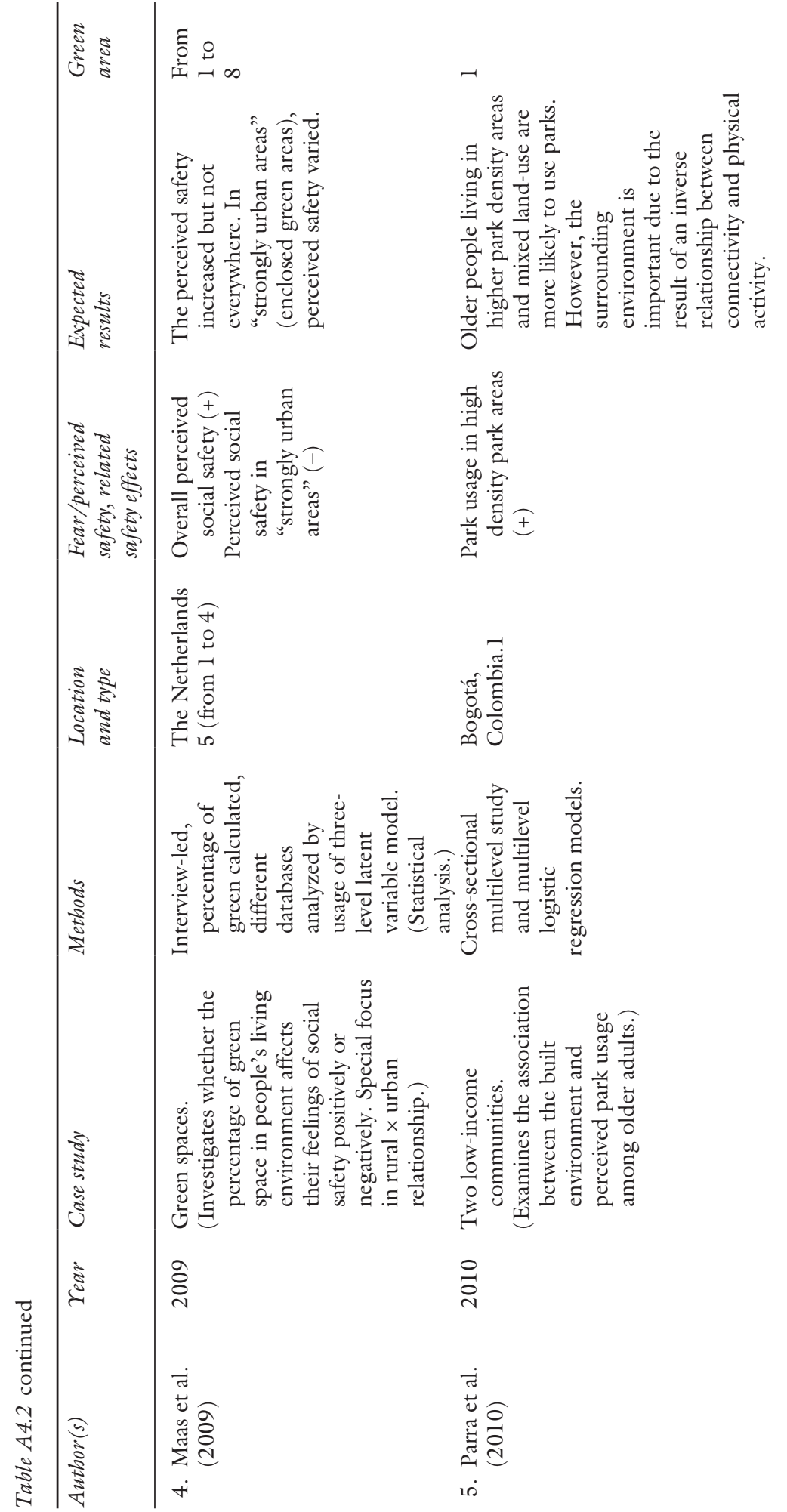



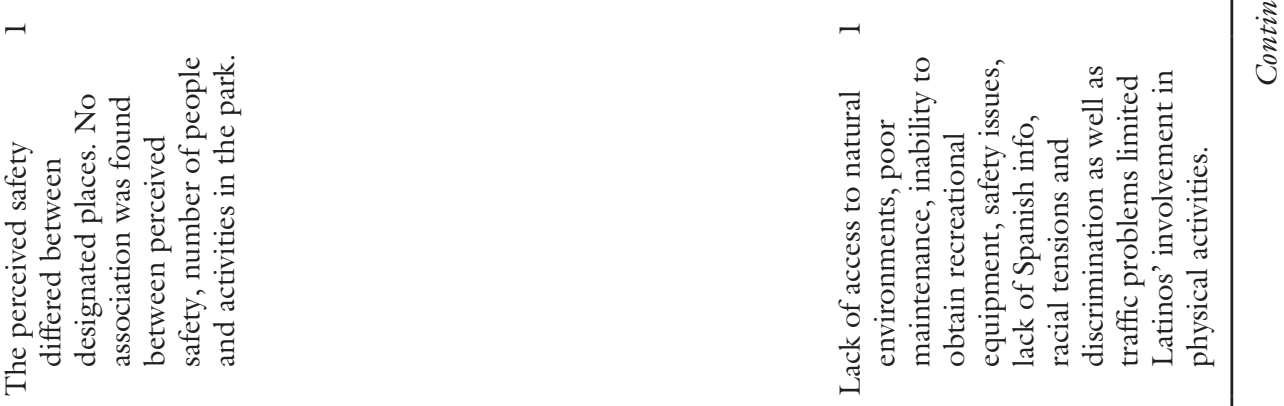

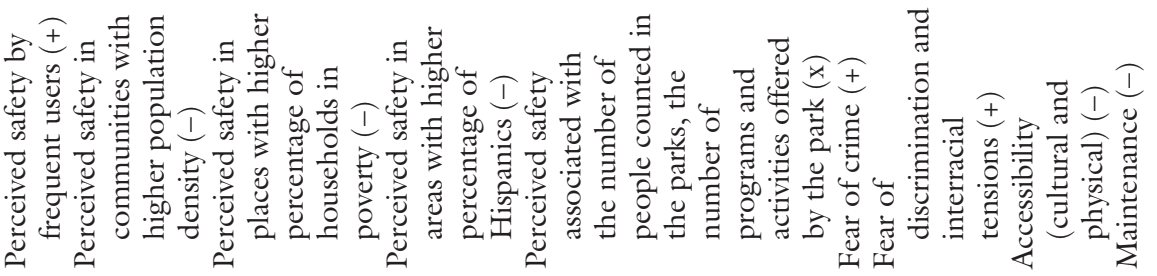
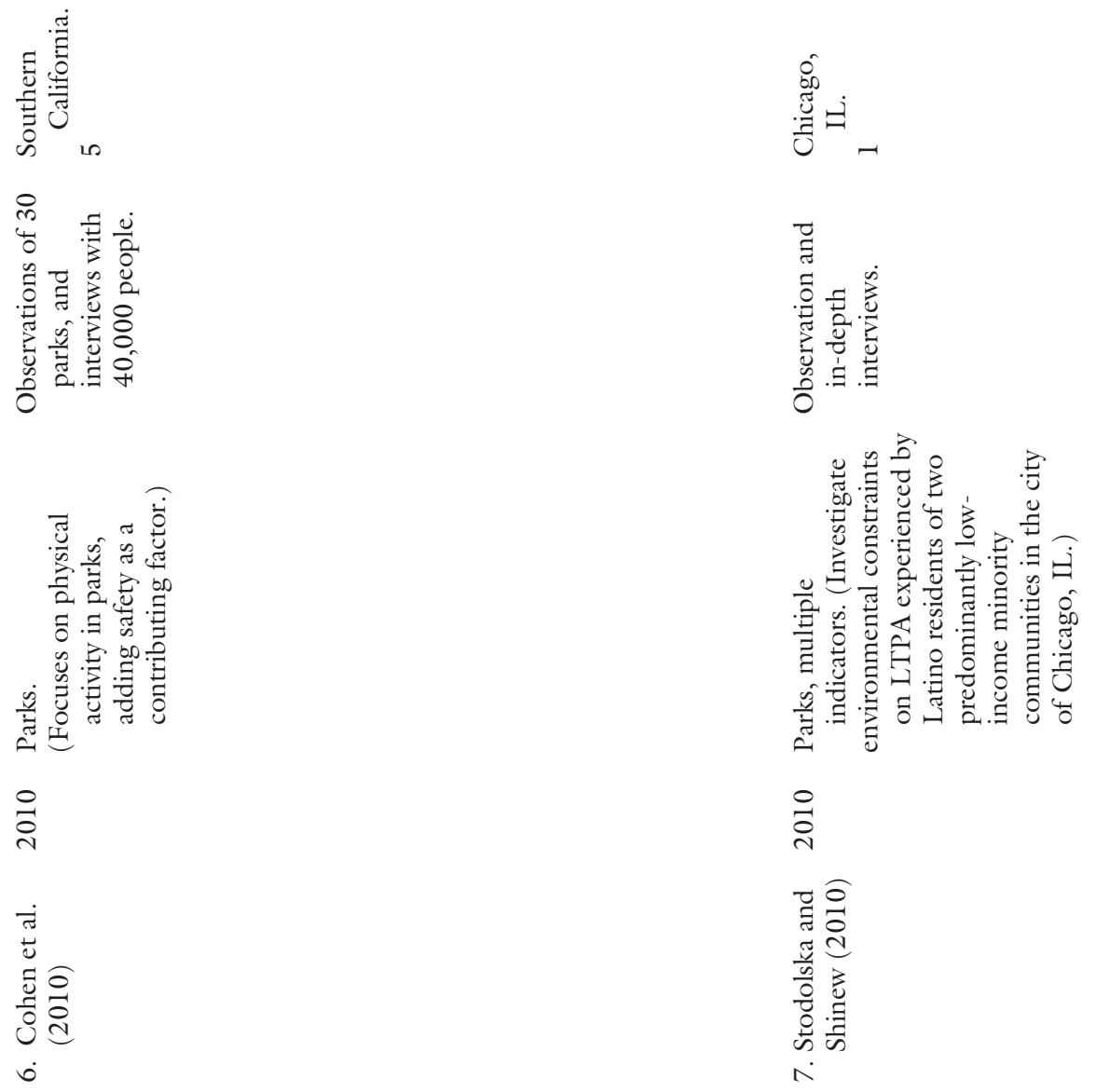
98 Vania Ceccato et al.

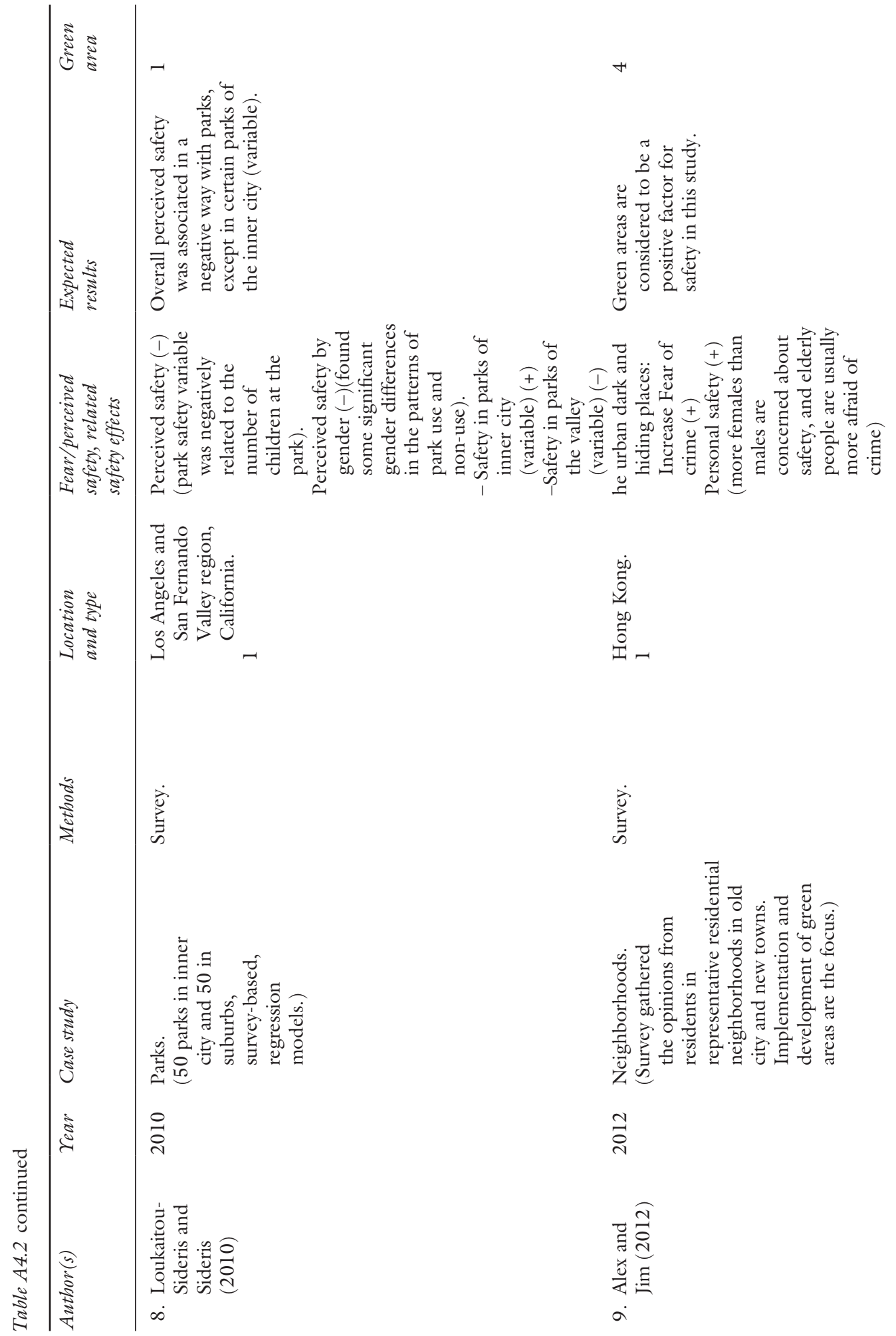




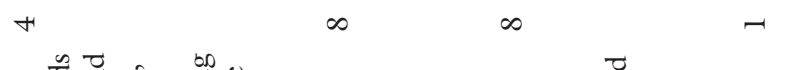

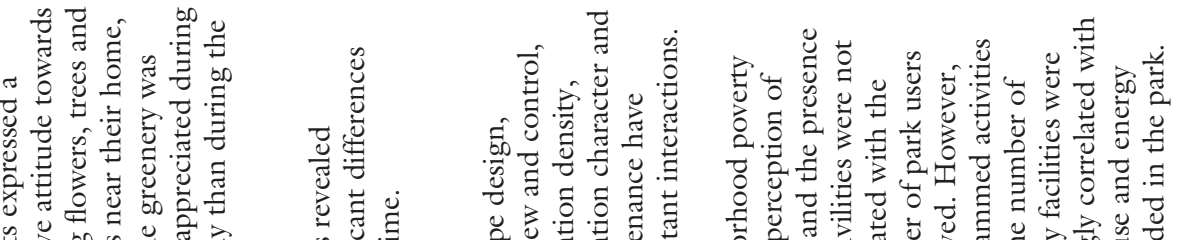
क z

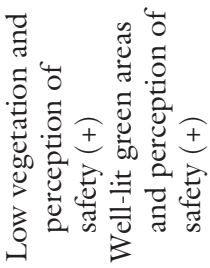
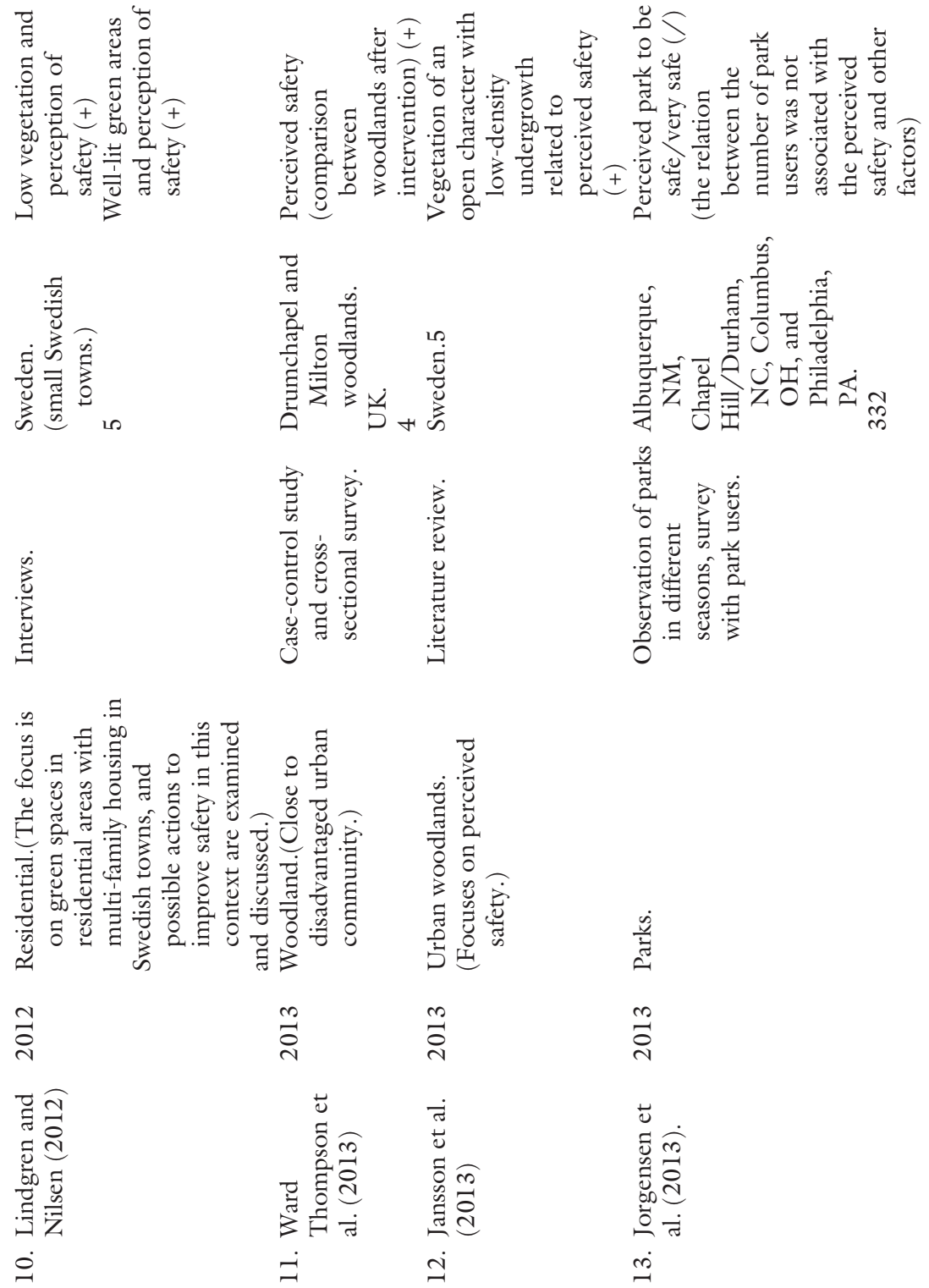
Vania Ceccato et al.

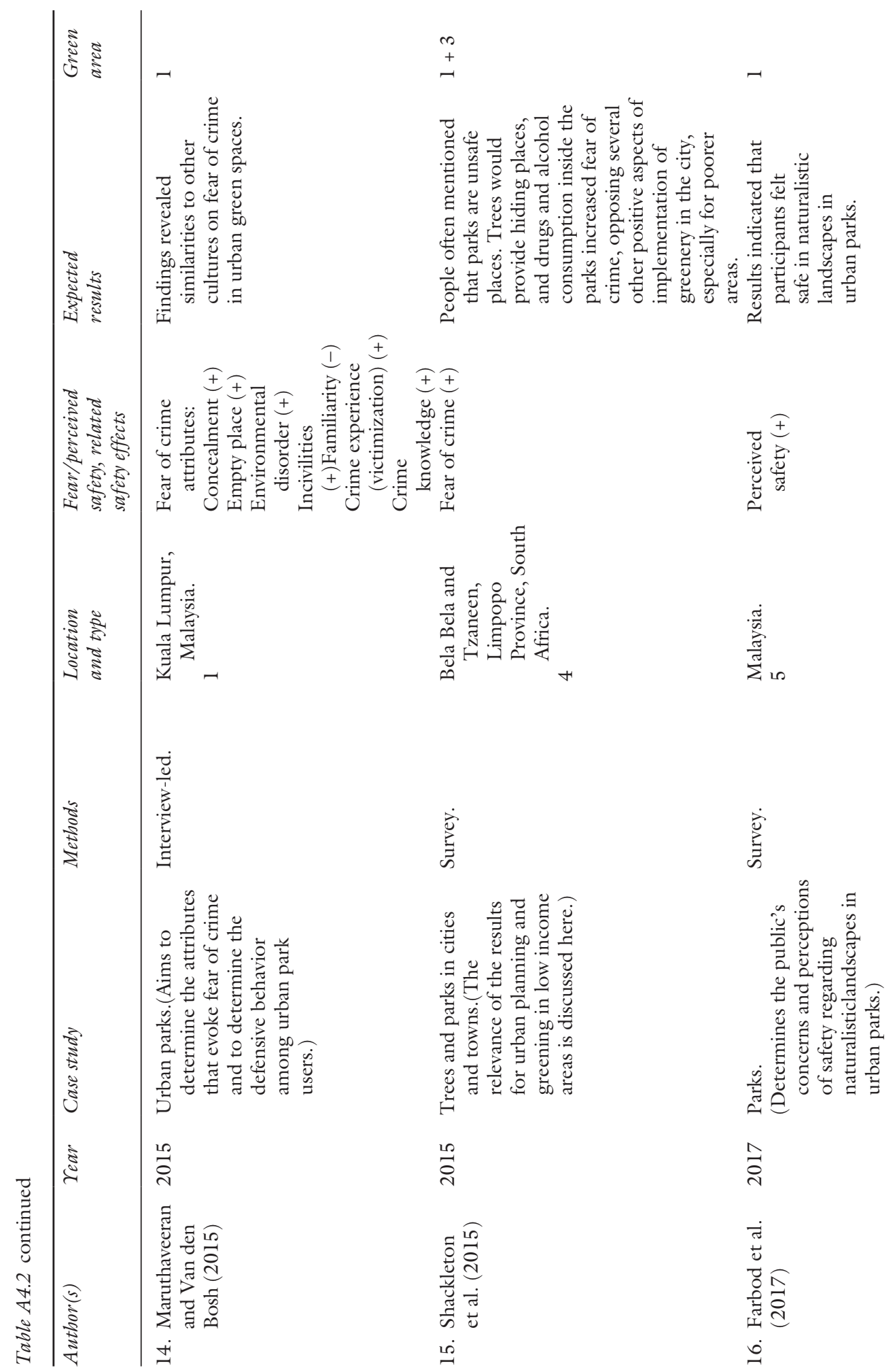



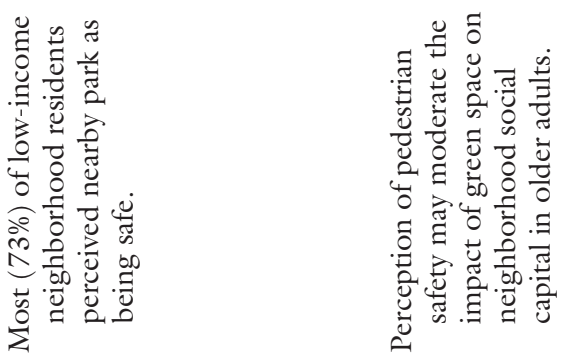

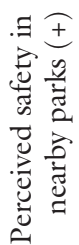

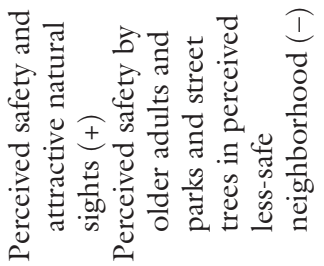

感

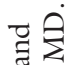

से

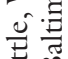

苞 $-N$

㐫

㐫

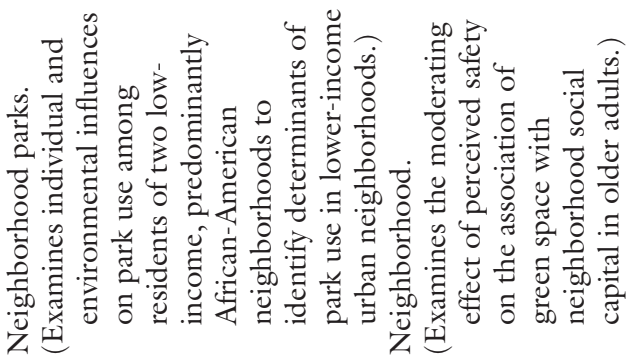

$\stackrel{\infty}{\circ}$

$\stackrel{\infty}{\stackrel{2}{*}}$

तं

苟市

สं

可

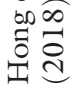

I

$\infty$

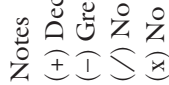



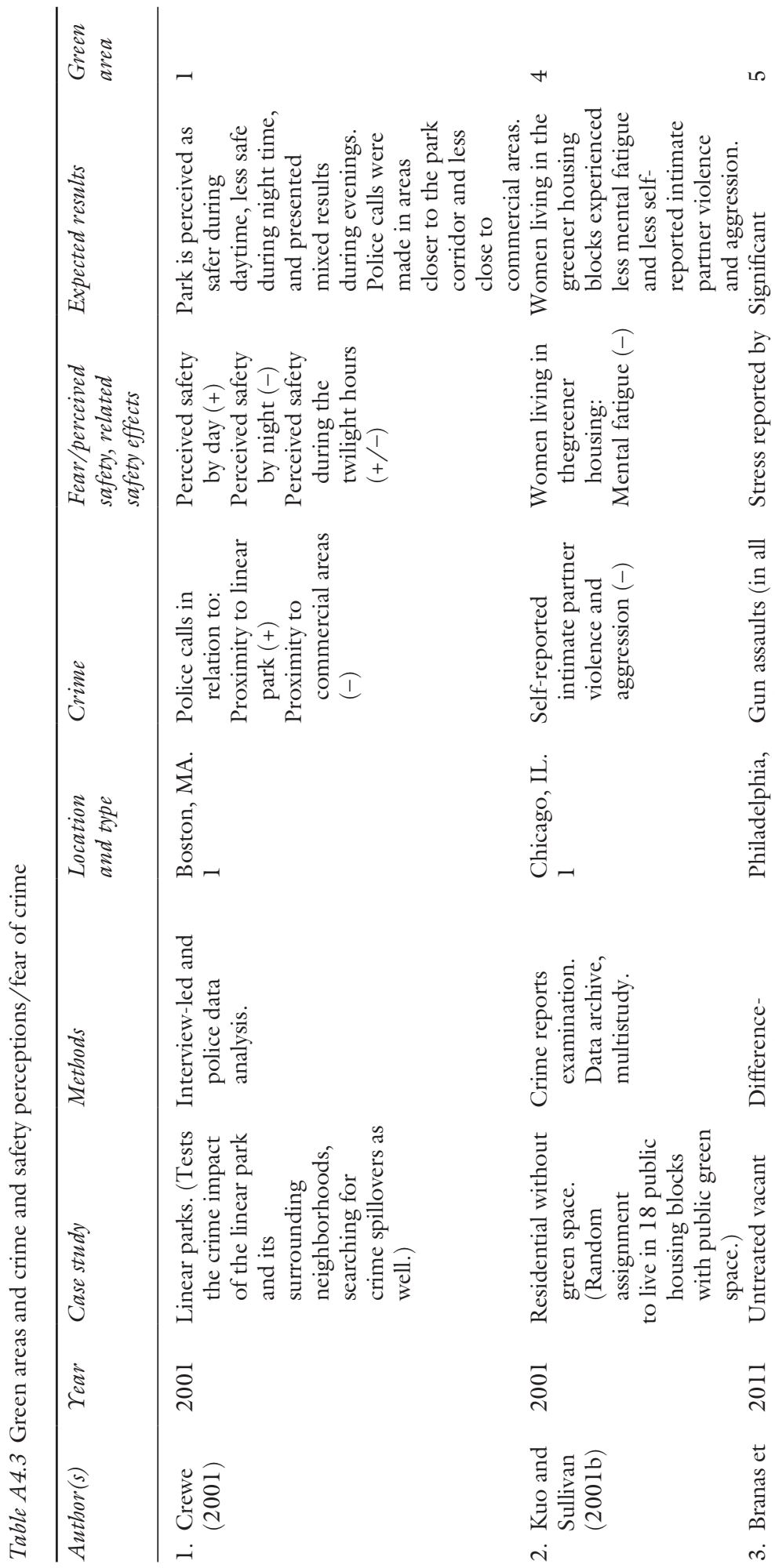

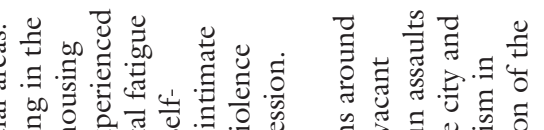

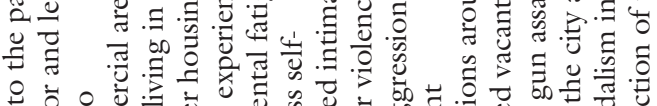



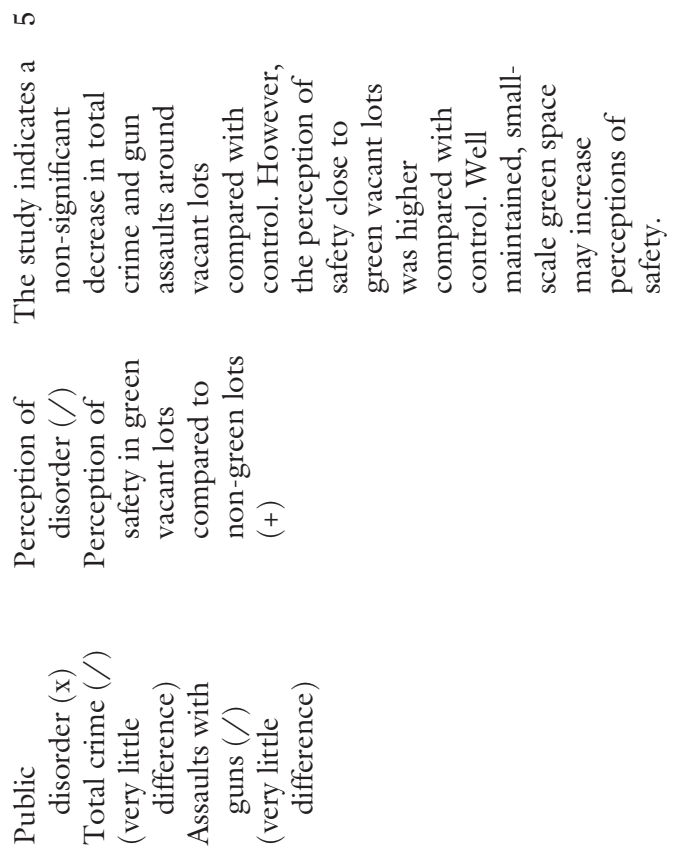

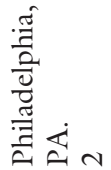

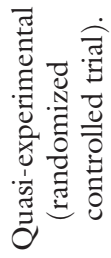

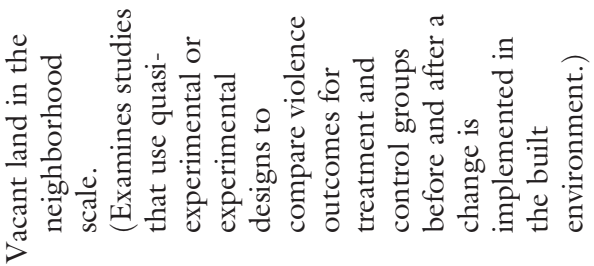

$$
\begin{aligned}
& \text { 웅 }
\end{aligned}
$$

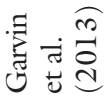

$$
\begin{aligned}
& \text { +ن }
\end{aligned}
$$

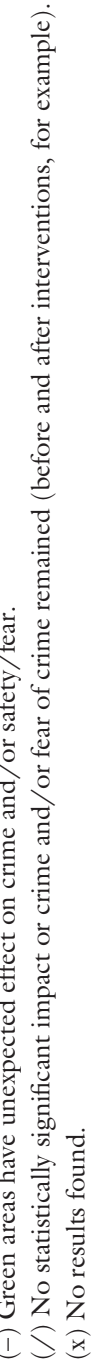




\section{Vania Ceccato et al.}

\section{References}

Alex, Y. H. Lo \& C. Y. Jim. (2012). Citizen attitude and expectation towards greenspace provision in compact urban milieu. Land Use Policy, 29, 577-586.

Aliprantis, D., \& Hartley, D. (2015). Blowing it up and knocking it down: The local and city-wide effects of demolishing high concentration public housing on crime. Journal of Urban Economics, 88, 67-81.

Armitage, R. (2013). Crime Prevention through Housing Design: Policy and Practice. Basingstoke: Palgrave Macmillan.

Babey, S. H., Tan, D., Wolstein, J., \& Diamant, A. L. (2015). Neighborhood, family and individual characteristics related to adolescent park-based physical activity. Preventive Medicine, 76, 31-36.

Bogar, S., \& Beyer, K. M. (2015). Green space, violence, and crime: A systematic review. Trauma, Violence, and Abuse, 17, 160-171.

Bowers, K. (2014). Risky facilities: Crime radiators or crime absorbers? A comparison of internal and external levels of theft. Journal of Quantitative Criminology, 30, 389-414.

Box, S., Hale, C., \& Andrews, G. (1988). Explaining fear of crime. British Journal of Criminology, 28, 340-356.

Branas, C. C., Cheney, R. A., MacDonald, J. M., Tam, V. W., Jackson, T. D., \& Ten Have, T. R. (2011). A difference-in-differences analysis of health, safety, and greening vacant urban space. American Journal of Epidemiology, 174, 1296-1306.

Branas, C. C., South, E., Kondo, M. C., Hohl, B. C., Bourgois, P., Wiebe, D. J., \& MacDonald, J. M. (2018). Citywide cluster randomized trial to restore blighted vacant land and its effects on violence, crime, and fear. Proceedings of the National Academy of Sciences, 115, 2946.

Brantingham, P. J., \& Brantingham, P. L. (1984). Patterns in Crime. New York: Macmillan.

Brantingham, P. L., \& Brantingham, P. J. (1995). Criminality of place: Crime generators and crime attractors. European Journal on Criminal Policy and Research, 3, 1-26.

Ceccato, V. (2019). Fieldwork protocol as a safety inventory tool in public places. Criminal Justice Studies, 32, 165-188.

Ceccato, V., \& Hanson, M. (2013). Experiences from Assessing Safety in Vingis Park, Vilnius, Lithuania. Review of European Studies, 5, 1-16.

Chiesura, A. (2004). The role of urban parks for the sustainable city. Landscape and Urban Planning, 68, 129-138.

Clarke, R., \& Eck, J. (2007). Understanding risky facilities. Tool Guide No. 6. Retrieved from https://popcenter.asu.edu/content/understanding-risky-facilities (accessed 20 February 2020).

Clarke, R. C., \& Eck, J. E. (2005). Crime analysis for problem solvers in 60 small steps. https://popcenter.asu.edu/content/crime-analysis-problem-solvers-60-small-steps (accessed 20 February 2020).

Cohen, D. A., Han, B., Derose, K. P., Williamson, S., Marsh, T., Raaen, L., \& McKenzie, T. L. (2016). The paradox of parks in low-income areas: park use and perceived threats. Environment and Behavior, 48, 230-245.

Cohen, D. A., Marsh, T., Williamson, S., Derose, K. P., Martinez, H., Setodji, C., \& McKenzie, T. L. (2010). Parks and physical activity: Why are some parks used more than others? Preventive Medicine, 50(SUPPL.), S9-S12.

Cohen, L. E., \& Felson, M. (1979). Social change and crime rate trends: A routine activity approach. American Sociological Review, 44, 588-608.

Coley, R. L., Kuo, F. E., \& Sullivan, W. C. (1997). Where does community grow? The social context created by nature in urban public housing. Environment and Behavior, 29, 468-494.

Cozens, P. M., Saville, G., \& Hillier, D. (2005). Crime prevention through environmental design (CPTED): A review and modern bibliography. Property Management, 23, 328-356. 
Crewe, K. (2001). Linear parks and urban neighbourhoods: A study of the crime impact of the Boston South-west Corridor. Journal of Urban Design, 6, 245-264.

Day, K. (2009). Being feared: Masculinity and race in public space. In M. L. S. Farrall (Ed.), Fear of Crime: Critical Voices in an Age of Anxiety (pp. 82-107). New York: Routledge-Cavendish.

Donovan, G. H., \& Prestemon, J. P. (2012). The effects of trees on crime in Portland, Oregon. Environment and Behavior, 44, 3-30.

Ekblom, P. (2011). Deconstructing CPTED ... and reconstructing it for practice, knowledge management and research. European Journal on Criminal Policy and Research, 17, 7-28.

Ekblom, P. (2019). Sharpening up CPTED-towards an ontology based on crime science and ecology. In P. Ekblom \& R. Armitage (Eds.), Rebuilding Crime Prevention Through Environmental Design: Strengthening the Links with Crime Science. Abingdon, Oxon: Routledge.

Farbod, S., Kamal, M., \& Maulan, S. (2017). Safety perception and concerns in naturalistic landscapes of urban parks in Malaysia. Security Journal, 30, 106-122.

Freedman, M., \& Owens, E. G. (2011). Low-income housing development and crime. Journal of Urban Economics, 70, 115-131.

Garofalo, J., \& Laub, J. (1979). Fear of crime-broadening our perspective. Victomology, $3,242-253$.

Garvin, E. C., Cannuscio, C. C., \& Branas, C. C. (2013). Greening vacant lots to reduce violent crime: A randomised controlled trial. Injury Prevention, 19, 198-203.

Gilstad-Hayden, K., Wallace, L. R., Carroll-Scott, A., Meyer, S. R., Barbo, S., MurphyDunning, C., \& Ickovics, J. R. (2015). Research note: Greater tree canopy cover is associated with lower rates of both violent and property crime in New Haven, CT. Landscape and Urban Planning, 143, 248-253.

Giurgescu, C., Zenk, S. N., Templin, T. N., Engeland, C. G., Kavanaugh, K., \& Misra, D. P. (2017). The impact of neighborhood conditions and psychological distress on preterm birth in African-American women. Public Health Nursing, 34, 256-266.

Gómez, E., Baur, J. W. R., Hill, E., \& Georgiev, S. (2015). Urban parks and psychological sense of community. Journal of Leisure Research, 47, 388-398.

Goode, D., \& Collins, W. (2014). The different types of urban green spaces. Urban Rambles. http://urbanrambles.org/contact-urban-rambles (accessed 20 February 2020).

Groff, E., \& McCord, E. (2011). The role of neighborhood parks as crime generators. Security Journal, 25, 1-24.

Heinze, J. E., Krusky-Morey, A., Vagi, K. J., Reischl, T. M., Franzen, S., Pruett, N. K., .., Zimmerman, M. A. (2018). Busy streets theory: The effects of community-engaged greening on violence. American Journal of Community Psychology, 62, 101-109.

Higgins, J. P. T., \& Green, S. (2011). Cochrane Handbook for Systematic Reviews of Interventions. G. S. Higgins JPT (Ed.) https://training.cochrane.org/handbook (accessed 29 June 2019).

Hilborn, J. (2009). Dealing with Crime and Disorder in Urban Parks. Retrieved from www.cops.usdoj.gov (accessed 18 October 2019).

Hong, A., Sallis, J. F., King, A. C., Conway, T. L., Saelens, B., Cain, K. L., ..., Frank, L. D. (2018). Linking green space to neighborhood social capital in older adults: The role of perceived safety. Social Science \& Medicine, 207, 38-45.

Iqbal, A., \& Ceccato, V. (2015). Does crime in parks affect apartment prices? Journal of Scandinavian Studies in Criminology and Crime Prevention, 16, 97-121.

Iqbal, A., \& Ceccato, V. (2016). Is CPTED useful to guide the inventory of safety in parks? A study case in Stockholm, Sweden. International Criminal Justice Review, 26, 150-168.

Jackson, J., \& Gouseti, I. (Eds.). (2012). Fear of Crime: An Entry to the Encyclopedia of Theoretical Criminology. Chichester: Wiley-Blackwell.

Jacobs, J. (1961). The Death and Life of Great American Cities. New York: Vintage Books. 
Jansson, M., Fors, H., Lindgren, T., \& Wistrom, B. (2013). Perceived personal safety in relation to urban woodland vegetation-A review. Urban Forestry \& Urban Greening, $12,127-133$.

Jeffery, C. R. (1971). Crime prevention through environmental design. American Behavioral Scientist, 14, 598 .

Jeffery, C. R. (1977). Crime Prevention through Environmental Design. (2nd ed.). Beverly Hills: Sage.

Jorgensen, L. J., Ellis, G. D., \& Ruddell, E. (2013). Fear perceptions in public parks: Interactions of environmental concealment, the presence of people recreating, and gender. Environment and Behavior, 45, 803-820.

Kimpton, A., Corcoran, J., \& Wickes, R. (2017). Greenspace and crime: An analysis of greenspace types, neighboring composition, and the temporal dimensions of crime. Journal of Research in Crime and Delinquency, 54, 303-337.

Kondo, M. C., Andreyeva, E., South, E. C., MacDonald, J. M., \& Branas, C. C. (2018a). Neighborhood interventions to reduce violence. Annual Review of Public Health, 39, 253-271.

Kondo, M. C., Fluehr, J. M., McKeon, T., \& Branas, C. C. (2018b). Urban green space and its impact on human health. International Journal of Environmental Research and Public Health, 15(3).

Kondo, M. C., Han, S., Donovan, G. H., \& MacDonald, J. M. (2017). The association between urban trees and crime: Evidence from the spread of the emerald ash borer in Cincinnati. Landscape and Urban Planning, 157, 193-199.

Kondo, M. C., South, E. C., Branas, C. C., Richmond, T. S., \& Wiebe, D. J. (2017). The Association between urban tree cover and gun assault: A case-control and casecrossover study. American Journal of Epidemiology, 186, 289-296.

Kondo, M., Hohl, B., Han, S., \& Branas, C. (2016). Effects of greening and community reuse of vacant lots on crime. Urban Studies, 53, 3279-3295.

Kondo, M. C., Low, S. C., Henning, J., \& Branas, C. C. (2015). The impact of green stormwater infrastructure installation on surrounding health and safety. American Journal of Public Health, 105, el14-e121.

Kuo, F. E., Bacaicoa, M., \& Sullivan, W. C. (1998). Transforming inner-city landscapes: Trees, sense of safety, and preference. Environment and Behavior, 30, 28-59.

Kuo, F. E., \& Sullivan, W. C. (2001a). Environment and crime in the inner city does vegetation reduce crime? Environment and Behavior, 33, 343-367.

Kuo, F. E., \& Sullivan, W. C. (2001b). Aggression and violence in the inner city: Effects of environment via mental fatigue. Environment and Behavior, 33, 543-571.

Lindgren, T., \& Nilsen, M. R. (2012). Safety in residential areas. Tijdschrift voor Economische en Sociale Geografie, 103, 196-208.

Lorenc, T., Petticrew, M., Whitehead, M., Neary, D., Clayton, S., Wright, K., ..., Renton, A. (2013). Environmental interventions to reduce fear of crime: Systematic review of effectiveness. Systematic Reviews, 2, 1-10.

Los, M. (2002). Post-communist fear of crime and the commercialization of security. Theoretical Criminology, 6, 165-188.

Loukaitou-Sideris, A., \& Sideris, A. (2010). What brings children to the park? Analysis and measurement of the variables affecting children's use of parks. Journal of the American Planning Association, 76, 89-107.

Maas, J., Spreeuwenberg, P., van Winsum-Westra, M., Verheij, R. A., Vries, S., \& Groenewegen, P. P. (2009). Is green space in the living environment associated with people's feelings of social safety? Environment and Planning A, 41, 1763-1777.

Madge, C. (1997). Public parks and the geography of fear. Tijdschrift voor Economische en Sociale Geografie, 88, 237-250.

Maruthaveeran, S., \& Van den Bosh, C. K. (2015). Fear of crime in urban parks-What the residents of Kuala Lumpur have to say? Urban Forestry and Urban Greening, 14, 702-713. 
Moher, D., Liberati, A., Tetzlaff, J., \& Altman, D. (2009). Preferred reporting items for systematic reviews and meta-analyses: The PRISMA statement. PLoS Med, 6, el000097.

Mulliner, E., \& Maliene, V. (2011). An introductory review to the special issue: Attractive places to live. Urban Design International, 16, 147-152.

Newman, O. (1972). Defensible Space-Crime Prevention through Urban Design. New York: Collier Books.

Pain, R., \& Smith, S. J. (2008). Fear: Critical geopolitics and everyday life. In R. Pain \& S. J. Smith (Eds.), Fear: Critical Geopolitics and Everyday Life (pp. 1-24). Aldershot: Ashgate.

Parra, D. C., Gomez, L. F., Fleischer, N. L., \& David Pinzon, J. (2010). Built environment characteristics and perceived active park use among older adults: Results from a multilevel study in Bogotá. Health and Place, 16, 1174-1181.

Poyner, B. (1994). An evaluation of walkway demolition on a British housing estate. In R. V. Clarke (Ed.), Situational Crime Prevention-Successful Case Studies (pp. 59-73). USA: Lynne Rienner Publishers.

Reynald, D. M. (2010). Guardians on guardianship: Factors affecting the willingness to supervise, the ability to detect potential offenders, and the willingness to intervene. Journal of Research in Crime and Delinquency, 47, 358-390.

Saville, G. (2019). Third Generation of CPTED. www.alternation.ca (accessed 12 January 2020).

Shackleton, S., Chinyimba, A., Hebinck, P., Shackleton, C., \& Kaoma, H. (2015). Multiple benefits and values of trees in urban landscapes in two towns in northern South Africa. Landscape and Urban Planning, 136, 76-86.

Spader, J., Schuetz, J., \& Cortes, A. (2015). Fewer vacants, fewer crimes? Impacts of neighborhood revitalization policies on crime. Regional Science and Urban Economics, $60,73-84$.

Stodolska, M., \& Shinew, K. J. (2010). Environmental constraints on leisure time physical activity among Latino urban residents. Qualitative Research in Sport and Exercise, 2, 313-335.

Talen, E., \& Koschinsky, J. (2014). Compact, walkable, diverse neighborhoods: Assessing effects on residents. Housing Policy Debate, 24, 717-750.

Troy, A., \& Grove, J. M. (2008). Property values, parks, and crime: A hedonic analysis in Baltimore, MD. Landscape and Urban Planning, 87, 233-245.

Troyer, R. J., \& Wright, R. D. (1985). Community response to crime: Two middle-class anti-crime patrols. Journal of Criminal Justice, 13, 227-241.

UN-Habitat (2019). Safer Cities Programme. Retrieved from http://fukuoka.unhabitat. org/programmes/detail04_01_en.html (accessed 12 December 2019).

UNHSP, The United Nations Human Settlements Programme (2007). Enhancing Urban Safety and Security: Global Report on Human Settlements. Retrieved from www. un.org/ruleoflaw/files/urbansafetyandsecurity.pdf (accessed 20 February 2020).

Ward Thompson, C., Roe, J., \& Aspinall, P. (2013). Woodland improvements in deprived urban communities: What impact do they have on people's activities and quality of life? Landscape and Urban Planning, 118, 79-89.

Vaughan, C. A., Colabianchi, N., Hunter, G. P., Beckman, R., \& Dubowitz, T. (2018). Park use in low-income urban neighborhoods: Who uses the parks and why? Journal of Urban Health, 95, 222-231.

Wolfe, M. K., \& Mennis, J. (2012). Does vegetation encourage or suppress urban crime? Evidence from Philadelphia, PA. Landscape and Urban Planning, 108, 112-122.

Wyant, B. R. (2008). Multilevel impacts of perceived incivilities and perceptions of crime risk on fear of crime: Isolating endogenous impacts. Journal of Research in Crime and Delinquency, 45, 39-64.

Ye, C., Chen, Y., \& Li, J. (2018). Investigating the influences of tree coverage and road density on property crime. ISPRS International Journal of Geo-Information, 7, 1-14. 